\title{
Phase transformation induces plasticity with negligible damage in Ceria-stabilized zirconia-based ceramics
}

Aléthéa Liens ${ }^{\mathrm{a}, \mathrm{b}}$, Helen Reveron ${ }^{\left.\mathrm{a},{ }^{*}\right)}$, Thierry Douillard ${ }^{\mathrm{a}}$, Nicholas Blanchard ${ }^{\mathrm{c}}$, Vanni Lughi $^{\text {d, }}$, Valter Sergo ${ }^{\text {d,e }}$, René Laquai ${ }^{\mathrm{f}}$, Bernd R. Müller ${ }^{\mathrm{f}}$, Giovanni Bruno ${ }^{\mathrm{f}}$, Sven Schomer ${ }^{\mathrm{g}}$, Tobias Fürderer $^{\mathrm{g}}$, Erik Adolfsson ${ }^{\mathrm{h}}$, Nicolas Courtois ${ }^{\mathrm{b}}$, Michael Swain ${ }^{\mathrm{i}, \mathrm{j}}$, Jérôme Chevalier ${ }^{\mathrm{a}}$

${ }^{a}$ Université de Lyon-INSA de Lyon, MATEIS CNRS UMR 5510, 20 Avenue Albert Einstein, F69621 Villeurbanne Cedex, France

${ }^{b}$ ANTHOGYR, 2237 Avenue André Lasquin, 74700 Sallanches, France

${ }^{c}$ Université de Lyon, Université Claude Bernard Lyon 1, CNRS, Institut Lumière Matière, F69622 Villeurbanne, France

${ }^{d}$ Engineeering and Architecture Dept., University of Trieste, Via Valerio 6a, 34127 Trieste, Italy

${ }^{e}$ Faculty of Health Sciences, University of Macau, SAR Macau, China

${ }_{B}$ BAM, Bundesanstalt für Materialforschung und -Prüfung, Unter den Eichen 87, 12205 Berlin, Germany

${ }^{g}$ DOCERAM, MOESCHTER GROUP Holding GmbH \& Co. KG, Hesslingsweg 65 - 67, 44309 Dortmund, Germany

${ }^{h}$ Ceramic Materials, Swerea IVF AB, 43153 Mölndal, Sweden

${ }^{i} A M M E$, University of Sydney, NSW 200, Australia

${ }^{j}$ Engineering, Don State Technical University, Rostov-on Don, 344010 Russia

*Corresponding author: helen.reveron@insa-lyon.fr; Tel.: +33-4-72436239

\begin{abstract}
Ceramics and their composites are in general brittle materials because they are predominantly made up of ionic and covalent bonds that avoid dislocation motion at room temperature. However, a remarkable ductile behavior has been observed on newly developed $11 \mathrm{~mol} . \%$ ceria-stabilized zirconia (11Ce-TZP) composite containing fine alumina (8vol.\% $\left.\mathrm{Al}_{2} \mathrm{O}_{3}\right)$ and elongated strontium hexa-aluminate $\left(8 \mathrm{vol} \% \mathrm{SrAl}_{12} \mathrm{O}_{19}\right)$ grains. The assynthesized composite also has shown full resistance to Low Temperature Degradation (LTD), relatively high strength and exceptionally high Weibull modulus, allowing its use in a broader range of biomedical applications. In this study, to deepen the understanding of
\end{abstract}


plastic deformation in Ce-TZP based composites that could soon be used for manufacturing dental implants, different mechanical tests were applied on the material, followed by complete microstructural characterization. Distinct from pure Ce-TZP material or other zirconia-based ceramics developed in the past, the material here studied can be permanently strained without affecting the Young modulus, indicating that the ductile response of tested samples cannot be associated to damage occurrence. This ductility is related to the stressinduced tetragonal to monoclinic $(t-m)$ zirconia phase transformation, analogue to Transformation-Induced Plasticity (TRIP) steels, where retained austenite is transformed to martensite. The aim of this study is to corroborate if the observed plasticity can be associated exclusively to the zirconia $t-m$ phase transformation, or also to microcraking induced by the transformation. The $t-m$ transformed-zones produced after bending and biaxial tests were examined by X-ray refraction and SEM/TEM coupled with Raman. The results revealed that the observed elastic-plastic behavior occurs without extensive microcracking, confirming a purely elastic-plastic behavior driven by the phase transformation (absence of damage).

Keywords: Zirconia; Ceria; Ceramic matrix composite; Plasticity; Phase transformation

\section{Introduction}

Due to their excellent mechanical properties, aesthetics and biocompatibility, YttriaStabilized-Zirconia ceramics (in particular with 3 mol.\% of yttria or 3Y-TZP) have been extensively used in the dental field, especially for restorations and implants. Their outstanding mechanical properties, above all toughness (when compared to other ceramics), result from $i$ ) the stress-induced tetragonal to monoclinic $(t-m)$ zirconia phase transformation, a mechanism referred to as "phase transformation toughening" [1-2] and ii) from the possibility to reach full-densification while retaining very fine zirconia grains (typically $<200 \mathrm{~nm}$ ). The stressinduced $t-m$ transformation starts at the crack-tip and is accompanied by $3-4$ vol.\% expansion. As a consequence of the volume expansion, the crack is put under compression and its propagation is hindered.

Unfortunately, 3Y-TZP can undergo an unfavourable spontaneous $t-m$ zirconia phase transformation at the surfaces in contact with water, be it liquid or vapour. This phenomenon, known as Low Temperature Degradation (LTD) or "aging", may lead to microcracking, grain pull-out and an increase of the surface roughness. In the worst of cases, it has led to deleterious effects on implants in vivo, premature failures or degradation of the osseous 
integration [3-7]. It is noteworthy that aging issues have led to the abandon of 3Y-TZP in the orthopaedic field, after the failure of hundreds of Prozyr ${ }^{\circledR}$ femoral ball heads only few months after implantation [6]. Moreover, 3Y-TZP remains substantially flaw-sensitive, which increases the failure probability if the ceramic processing is not well controlled. To overcome all these issues, additions of other oxides or microstructural improvements have been applied on Y-TZP systems [8-13], but even so, aging remains a concern, especially when trivalent cations are used. This is due to the fact that aging is directly linked to the oxygen vacancies created when stabilizing with a trivalent cation, as is the case with yttrium addition [6]. For this reason, cerium is an attractive alternative for stabilizing biomedical-grade zirconia: the tetravalent nature of cerium maintains the charge neutrality of the system after the substitution (no oxygen vacancies are generated) and, consequently, the aging resistance is excellent [14, $15]$.

Ceria-stabilized (Ce-TZP) ceramics display also higher toughness when compared with 3Y-TZP ( $>10.0 \mathrm{MPa} . \sqrt{\mathrm{m}}$ ), due to their ability to initiate stress-induced $t$ - $m$ phase transformation at lower stresses [16]. The only limitation of pure Ce-TZP ceramics is their relatively low strength $(\sim 500-600 \mathrm{MPa})$ : firstly, lower strength is associated with the inevitable grain growth that occurs during sintering when zirconia is stabilized with ceria [17]. Secondly, in very transformable Ce-TZP ceramics, the $t-m$ transformation takes place before failure and the strength will be dictated by the critical stress to induce the $t-m$ zirconia phase transformation $\left(\sigma_{c}{ }^{t-m}\right)$ : the higher the critical stress, the higher the ceramic strength provided significant pre-existing flaws are not present [18]. This is often called "transformation-limited strength phenomenon".

During the past two decades, researchers have increased Ce-TZP strength by developing composites since the immiscible second phases can hinder the grain growth. Among them, the Ce-TZP/alumina system has been widely studied and developed [19]. CeTZP/alumina composites have shown attractive mechanical properties due to zirconia grain refinement compared to pure Ce-TZP ceramics [20-24]. Other Ce-TZP-based systems containing aluminates have also shown improved strength [25-32]. However, even though the strength and toughness of Ce-TZP based composites were enhanced due to the introduction of second and third phases, most of these materials still behave as brittle ceramics, since their failure occurs before extensive $t-m$ phase transformation, which in turn translates in relatively low Weibull moduli [33]. Therefore, there is still room for improvements in the field of highly transformable Ce-TZP-based ceramics, in order to reach acceptable strength, high toughness and a significant amount of transformation-induced plasticity before failure. To achieve this 
goal, the simultaneous control of several interacting factors must be accomplished: stabilization degree, cation nature, zirconia grain size and secondary phases' nature and shape.

In this context, within the framework of the LONGLIFE European Project ("Advanced multifunctional zirconia ceramics for long-lasting implants", $7^{\text {th }}$ European Framework Program) a new type of Ce-TZP-based composite was developed [34]. Specifically, a fully dense ceramic, with a ceria-stabilized zirconia matrix (10.5 mol.\% Ce-TZP), containing equiaxed alumina ( 8 vol.\% $\left.\quad \mathrm{Al}_{2} \mathrm{O}_{3}\right)$ and elongated strontium hexa-aluminate ( 8 vol.\% $\left.\mathrm{SrAl}_{12} \mathrm{O}_{19}\right)$ as second phases, has resulted in an extremely fine-grained ceramic $(<1 \mu \mathrm{m}$ for the zirconia phase), with relatively high strength, full resistance to LTD and very high reliability (Weibull modulus $m=60$ ) [35]. Mechanical tests performed on this composite revealed a behaviour which was not purely elastic, with a significant strain to failure for a ceramic material. This behaviour can be related to a transformation-induced plasticity mechanism [35-40] first described by Garvie et al. in 1975 [39] from which the concept of "ceramic steel" was developed. Indeed, the $t-m$ phase transformation generated parallel transformation bands (when the composite was tested in four-point bending, 4PB) or starshaped zones (when tested in piston-on-three balls fixtures, P3B); transformed regions started to appear at a given value of stress $\left(\sigma_{c}^{t-m}\right)$ on the tensile side of samples, and continued developing until fracture $[35,41]$.

Grain-boundary microcracking associated with transformation plasticity has been reported in pure stabilized Mg-PSZ ( $8 \mathrm{~mol} \% \mathrm{MgO}, 50-\mu \mathrm{m}$ grain size) [42] and Ce-TZP (12 $\mathrm{mol} \% \mathrm{CeO}_{2}, 1.2-\mu \mathrm{m}$ grain size) [43] subjected to uniaxial compressive tests with a superimposed pressure. Microcracks were found to align with the compression axis and their density increased linearly with the extent of transformation $[43,44]$. In the case of Ce-TZP, transformation texture of both the remaining tetragonal phase and the newly formed monoclinic phase was observed [43]. It has been proposed that in uniaxial compression tests with superimposed hydrostatic compression, the primary mechanical force responsible for crack formation originates from the shear component of $t-m$ phase transformation, which can generate microcracks along the grain boundaries [44]. Moreover, in brittle zirconia ceramics such as 3Y-TZP, direct TEM (Transmission Electron Microscopy) evidence for substantial microcracking was also reported after fatigue deformation, while transformation plasticity was dominant in Mg-PSZ [42].

However, as only few studies have been devoted to very transformable Ce-TZP based composites with refined microstructure, it remains still unclear if the localized transformation plasticity is accompanied by extensive damage induced by the transformation, limiting 
therefore the strength (especially in fatigue) of these materials. TEM was used to characterize microcracking at the grain-boundary termination of transformed monoclinic twin laths in a study of the cyclic fatigue of $\mathrm{Ce}-\mathrm{TZP} / \mathrm{Al}_{2} \mathrm{O}_{3}[45]$, but no microcracking was detected within the transformation zones in Ce-TZP/ $/ \mathrm{Al}_{2} \mathrm{O}_{3}$ specimens containing $\mathrm{MnO}\left(\mathrm{Ce}-\mathrm{TZP} / \mathrm{Al}_{2} \mathrm{O}_{3} / \mathrm{MnO}\right)$ [46]. Moreover, a shape-memory-like behaviour in Ce-TZP and Ce-TZP/ $/ \mathrm{Al}_{2} \mathrm{O}_{3}$ ceramics has been associated with complete reversibility of the $t-m$ zirconia phase transformation, which suggests that microcracking is unlikely [47]. Therefore, in this context, it is important to understand if the $t-m$ stress-induced transformation in the aforementioned recently developed $\mathrm{Ce}-\mathrm{TZP} / \mathrm{Al}_{2} \mathrm{O}_{3} / \mathrm{SrAl}_{12} \mathrm{O}_{19}$ composites leads to microcracking triggered by the transformation. As previously reported, the mechanical characterization by loading-unloading tests did not reveal a significant change of the Young's modulus in the plastic region, which behaviour was confirmed by ultrasonic resonance measurements [35].

In the literature, a few studies have shown that after mechanical loading (e.g. indentation of Ce-TZP ceramics), the $t-m$ zirconia phase transformation can generate microcracking and dislocations, associated with deep scratches, gouges or cracks within the grains $[40,48-50]$. However, cracks at the grain boundaries and also dislocations were mainly attributed to the very high stresses reached in indented regions and not specifically to the $t-m$ transformation. Cross sections of 3-YTZ aged samples have also been examined by SEM and TEM to demonstrate that microcracking, here related to the spontaneous $t$ - $m$ transformation, occurred at the surface of the material during aging [51, 52].

Less conventional X-ray refraction techniques (not to be confused with the more standard X-Ray Diffraction, XRD) can also be used for microcracking characterization, as these techniques allow determining the internal surfaces and interfaces in the nanomicrometer range [53-58]. One of the main advantages of X-ray refraction is that nanoparticles, cracks and pores can be easily detected in as-prepared materials, avoiding, for example, TEM thin foil preparation. Also, as X-ray refraction is sensitive to orientation, preferential alignment or positioning of cracks can be examined [53]. An investigation of $\mathrm{SiC}$ and alumina materials has shown that the internal surface density, pores sizes and their spatial distribution can be quantitatively characterized by X-ray refraction topography (XRRT) [54]. This technique was also used for characterizing fibre cracks, microcracks and debonding on a glass-fibre reinforced polyoximethylene (POM-GF) composite, after mechanical loading and accelerated aging [55]. Several techniques based on the X-ray refraction phenomenon can be applied for $2 \mathrm{D} / 3 \mathrm{D}$ microstructural characterization as for example $i$ ) X-ray refraction topography (XRRT, based on the scanning of the sample using a X-ray beam), ii) X-ray 
refraction radiography (XRRR, or direct 2D imaging typically implemented using a synchrotron source) and iii) X-ray refraction tomography (XRCT). In particular, XRRT techniques are based on Ultra Small Angle Scattering (USAXS) produced on microstructural features causing refraction at small angles of between several seconds and a few minutes of arc, as the refractive index of X-rays is nearly unity. Moreover, due to the short X-ray wavelength $(\sim 0.1 \mathrm{~nm})$, deviations of the X-ray beam due to the refraction can reveal internal surfaces and interfaces of nanometer dimensions $(1 \mathrm{~nm})$. The term topography indicates that the technique is concerned with the topography of internal refracting microstructural features (characteristics and distribution). For further details regarding X-ray refraction, the reader can refer to [53].

The main goal of this work is to clarify if the elastic-plastic transformation behaviour observed during the mechanical loading of Ce-TZP-based composites occurs with or without damage. In this study, we use XRRT to determine the internal specific surface in transformed and untransformed zones in Ce-TZP/ $/ \mathrm{Al}_{2} \mathrm{O}_{3} / \mathrm{SrAl}_{12} \mathrm{O}_{19}$ and $\mathrm{SEM} / \mathrm{TEM}$ for direct observations. As it will be shown, our results corroborate and support the absence of significant microcracking.

\section{Methods}

\subsection{Materials processing and initial characterization}

The studied materials have a composition of 84 vol\% $\mathrm{ZrO}_{2}\left(11 \mathrm{~mol} . \% \mathrm{CeO}_{2}\right), 8$ vol.\% of $\mathrm{Al}_{2} \mathrm{O}_{3}$ and 8 vol.\% of $\mathrm{SrAl}_{12} \mathrm{O}_{19}$. Henceforth the material will be referred to as $\mathrm{ZA}_{8} \mathrm{Sr}_{8} \mathrm{Ce}_{11}$, where Z: Zirconia, A: Alumina and S: Strontium Aluminate. Compared to materials developed in $[34,35]$, the content of $\mathrm{CeO}_{2}$ was set to $11 \mathrm{~mol} . \%$ in order to compensate microstructural changes related to the scaling-up (powder-synthesis, pressing and sintering were conducted at the industrial-scale and as a consequence, larger zirconia grains were obtained). Ceramics were manufactured by DOCERAM GmbH (Dortmund, Germany) from spray-dried powders synthesized and provided by DAIICHI KIGENSO KAGAKU KOGYO CO. LTD (Osaka, Japan). The powders were Cold Isostatic Pressed (CIP) at $300 \mathrm{MPa}$ and pressureless sintered at $1450^{\circ} \mathrm{C}$ for $1 \mathrm{~h}$ in air. The average grain size of zirconia was estimated from the linear-intercept method using 1.56 as correction factor. For alumina, only the maximum diameter was considered, as grains are spherical-shaped. To evaluate the size of aluminate grains, the maximum length and width of elongated grains were estimated. The spontaneous $t-m$ transformation temperature $\left(T_{t-m}\right)$ was assessed by cooling a four-point 
bending bar (width $b=4 \mathrm{~mm}$; thickness $h=3 \mathrm{~mm}$ and length $l_{0}=41 \mathrm{~mm}$ ) suspended over a liquid nitrogen bath: the $T_{t-m}$ was assumed to be the surface temperature of the sample, measured with a thermocouple, when the martensitic transformation took place and the sample spontaneously cracked due to the generalized volume expansion (3-4 vol.\% that accompanies $t-m$ transformation). Density was determined by Archimedes' method according to the C373-88(2006) ASTM standard and the relative density by correlating it with the theoretical density of a $\mathrm{ZA}_{8} \mathrm{Sr}_{8} \mathrm{Ce}_{11}$ composite $\left(5.86 \mathrm{~g} / \mathrm{cm}^{3}\right)$. Zirconia phase identification on as-sintered samples was performed by XRD (X-ray Bruker D8 diffractometer, Billerica, USA) using Ni-filtered $\mathrm{Cu} \mathrm{K \alpha}$ radiation $\left(0.1541 \mathrm{~nm}\right.$ ) between $2 \theta=27-33^{\circ}$ (step width of $0.05^{\circ}$ and an exposure time of $2 \mathrm{~s})$. The range $2 \theta=27-33^{\circ}$ includes reflections of $(111)_{\mathrm{m}},(-111)_{\mathrm{m}}$ and (101)t peaks used in determining the volumetric fractions of the $\mathrm{m}-\mathrm{ZrO}{ }_{2}\left(V_{m}\right)$ and $\mathrm{t}-\mathrm{ZrO}_{2}\left(V_{t}\right)$ phases from the intensities $\left(I_{m}\right.$ and $\left.I_{t}\right)$ of the diffraction peaks as [59]:

$$
V m=\frac{1.311 x}{1+0.311 x} \text { and } \quad V t=1-V m
$$

Where,

$$
x=\frac{\operatorname{Im}(-111)+\operatorname{Im}(111)}{\operatorname{Im}(-111)+\operatorname{Im}(111)+\operatorname{It}(101)}
$$

\subsection{Mechanical tests}

Disc shaped specimens (diameter $16 \mathrm{~mm}$, thickness $1 \mathrm{~mm}$ ) and rectangular bars (width $b=4 \mathrm{~mm}$; thickness $h=3 \mathrm{~mm}$ and length $l_{0}=41 \mathrm{~mm}$ ) were machined by using a $16 \mu \mathrm{m}$ diamond wheel followed by polishing down to 1 or $0.03 \mu \mathrm{m}$. Polishing was necessary to allow optical $(1 \mu \mathrm{m})$ and SEM $(0.03 \mu \mathrm{m})$ characterization of transformed zones. Samples were then annealed $\left(1200^{\circ} \mathrm{C}\right.$ for 30 minutes in air) to remove possible residual stresses generated when polishing.

Piston-on-three balls (P3B) and four-point bending (4PB) tests were performed on an universal hydraulic testing machine (INSTRON 8502, Nordwood, USA), at room temperature in air, at $0.5 \mathrm{~mm} / \mathrm{min}$. For P3B, the fixture used was composed of a pin $(1.6 \pm 0.2 \mathrm{~mm}$ diameter) and three $4.0 \mathrm{~mm}$ diameter steel balls $120^{\circ}$ apart, located on a $12 \mathrm{~mm}$ diameter circle, in agreement with the ISO 6872 standard. For 4PB, outer $(L)$ and inner $(l)$ spans' lengths of $L=35$ and $l=10 \mathrm{~mm}$ were used. The samples were subjected to load-unload cycles until the fracture. The testing machine was equipped with a linear variable differential transformer (LVDT, put in contact with the tensile surface) for accurate direct measurement of the displacement during tests. 
The Young's modulus $(E)$ was estimated by the resonance vibration method (ASTM

C1259-01, Grindo-Sonic tester) on 4PB samples before and after being deformed to 95\% of the failure load. For each sample, 30 resonant frequency measurements were carried-out and the standard deviation (SD) was calculated. The 4PB geometry was preferred for measurements because the frequency of vibration in bending mode is only a function of the cross-section and the length of the bar. During plastic deformation, the Young's modulus evolution was computed from the elastic region that appears in the stress-strain curve at each cycle (i.e. slopes of the loading/unloading curves).

\subsection{Characterisation of the t-m transformation features}

The transformed zones of $\mathrm{SrAl}_{12} \mathrm{O}_{19}$ specimens after mechanical tests observed on the tensile side were characterized by optical microscopy (ZEISS Axiophot microscope, Oberkochen, Germany) using Nomarski interference contrast. Additionally, SEM (ZEISS Supra 55, Oberkochen, Germany) characterization of the P3B transformed zone was also performed at low accelerating voltage, allowing observation of the microstructure without the usual requirement of a metallized surface coating. Raman spectra were also collected after failure on the tensile side of $\mathrm{P} 3 \mathrm{~B}$ and $4 \mathrm{~PB}$ samples using an InVia Raman microscope (Renishaw plc, Wotton-under-Edge, UK) equipped with a high-power $785 \mathrm{~nm}$ near infrared diode laser (Toptica Photonics AG, Gräfelfing, Germany) delivering $120 \mathrm{~mW}$ of laser power to the sample (x10 objective, N.A. 0.25). Raman data analysis was performed by using the R software environment [60] for statistical computing and graphics and the Fityk software [61] for curve fitting, allowing the mapping of monoclinic/tetragonal phase content. For each spectrum, the monoclinic volume fraction was calculated from peak areas according to Tabares and Anglada [62] based on Katagiri et al. [63] equations.

\subsection{Characterisation of potential microcracking by X-Ray Refraction Topography (XRRT)}

Untransformed and $t-m$ transformed zones of P3B tested sample were characterized by XRRT. This mechanical test was preferred because it leads to a larger transformed area, easier to analyze [35]. After the failure, one-half of the tested disc was mechanically ground, starting from the compression side until reaching a thickness of $230 \mu \mathrm{m}$ by using $15 \mu \mathrm{m}$ diamond wheel. This thinning procedure was necessary for decreasing the X-ray absorption by the sample and getting enough transmitted signal with the laboratory X-ray source here employed. For XRRT analysis, the sample was scanned in two perpendicular orientations (hereafter 
referred to as $0^{\circ}$ and $90^{\circ}$ ) [53]. Two-dimensional images of the material with a spatial resolution of $1000 \times 50 \mu \mathrm{m}^{2}$ (width $\mathrm{x}$ height) were processed.

Two detectors were used to measure the transmitted intensity $\left(I_{T}\right)$ and the refracted intensity $\left(I_{R}\right)$ and this was done with and without the sample (index 0 ). The refraction value $C_{m}$ multiplied by the thickness $d$ is calculated as follow:

$$
C_{m} \cdot d=\left[\left(\frac{I_{R}}{I_{R 0}}\right) /\left(\frac{I_{T}}{I_{T 0}}\right)\right]-1
$$

The linear absorption coefficient $\mu$ multiplied by the thickness $d$ can be obtained by:

$$
\mu . d=-\ln \frac{I_{T}}{I_{T 0}}
$$

The term $C_{m} / \mu$ was computed in the two orientations $\left(0^{\circ}\right.$ and $\left.90^{\circ}\right)$ for both transformed (centre of the disc) and untransformed (periphery of the disc) zones. Values of $C_{m} / \mu$ are proportional to the relative specific internal scattering surfaces of the investigated regions. XRRT experiment was performed on the same sample in order to avoid possible variations of the internal scattering surfaces due to microstructural changes in between different samples.

\subsection{Transmission Electron Microsocopy inside a transformation zone}

For performing TEM characterization of transformed material, a thin foil was milled in a transformation band of a tested 4PB specimen using the Focus Ion Beam (FIB) technique (FIB/SEM NVision 40 dual beam station, Carl Zeiss Microscopy GmbH, Oberkochen, Germany). This microscope combines a SIINT zeta FIB column (Seiko Instruments Inc. NanoTechnology, Japan) with a Gemini column. Firstly, a transformed band was localized by Scanning Electron Microscopy and then the TEM foil was prepared by successive abrasions using FIB $\left(\mathrm{Ga}^{+}\right.$ions accelerated between 2 and $\left.30 \mathrm{keV}\right)$. SEM imaging was done in high vacuum and with an accelerating voltage of $1.5 \mathrm{kV}$ during the FIB preparation of the TEM slice. To prepare the TEM foil, the analysed sample was first glued with a silver paint onto an aluminum stub. Then, the zone was coated with a carbon layer of about $30 \mathrm{~nm}$ using thermal evaporation (EM SCD500, Leica Microsystems GmbH, Wetzlar, Germany), in order to make the surface electrically conductive for FIB cutting. A first abrasion at $45 \mathrm{nA}$ for $30 \mu \mathrm{m}$ was followed by a second abrasion at $13 \mathrm{nA}$ for $5 \mu \mathrm{m}$ and then followed by a cleaning step performed at $3 \mathrm{nA}$ for $30 \mu \mathrm{m}$. Thereafter, the foil was glued on the TEM sample holder. In order to make the foil transparent to the electron beam, its thickness was decreased by successive abrasions at 700,150,50, 40 and $10 \mathrm{pA}$ respectively, until reaching a thickness around $100 \mathrm{~nm}$. Finally, thickness was further reduced in a Precision Ion Polishing System (PIPS, GATAN INC, Pleasanton, USA) at a voltage of $1.7 \mathrm{KeV}$ for 10 minutes, using a 
double modulator and a gun angle of $+/-5^{\circ}$. The conditions for the TEM foil preparation have been carefully adapted to avoid any zirconia phase transformation during these operations. Both SEM (ZEISS Supra 55, Oberkochen, Germany, with an accelerating voltage of $1.5 \mathrm{kV}$ and without conductive coating) and TEM (HRTEM- JEOL 2010F, Tokyo, Japan) characterizations were performed on the prepared TEM foil.

\section{Results}

\subsection{Materials characterization}

The as-sintered ceramics were composed of zirconia ( $\mathrm{Z}: 0.9 \pm 0.4 \mu \mathrm{m})$, alumina (A: $0.3 \pm 0.1 \mu \mathrm{m}$ ) and hexa-aluminate (S: $2.8 \pm 1.7 \mu \mathrm{m}$, aspect ratio of $4 \pm 4$ ) grains (Figure 1a), homogeneously distributed (Figure 1b). Composites were fully dense ( $>99.9 \%$ of the theoretical density) and fully tetragonal $\left(\mathrm{t}-\mathrm{ZrO}_{2}\right)$ zirconia was obtained [34] as confirmed by X-ray diffraction (XRD) (Figure 1c). The $t$ - $m$ transformation temperature $\left(\mathrm{T}_{\mathrm{t}-\mathrm{m}}\right)$ of $\mathrm{ZA}_{8} \mathrm{Sr}_{8} \mathrm{Ce}_{11}$ composite sintered at $1450^{\circ} \mathrm{C}$ for $1 \mathrm{~h}$ was found to be near $-40^{\circ} \mathrm{C}$. This temperature can provide qualitative information about the material transformability as the lower the $\mathrm{T}_{\mathrm{t}-\mathrm{m}}$ the higher the zirconia stability. The studied material shows thus a considerable transformability as its spontaneous $t-m$ temperature is close to room temperature, in agreement with our previous work [64].

\subsection{Macroscopic features of transformed-zones in P3B and $4 P B$}

Optical images obtained with Nomarski contrast during loading/unloading tests on the tensile sides of $\mathrm{P} 3 \mathrm{~B}$ and $4 \mathrm{~PB}$ tested $\mathrm{ZA}_{8} \mathrm{Sr}_{8} \mathrm{Ce}_{11}$ samples are shown in Figure 2. The zirconia transformation was clearly visible in the shape of a star (P3B, Figure 2a) or regularly spaced parallel bands (4PB, Figure $2 \mathrm{~b}$ ). These bands were perpendicular to the main tensile stress direction. The fracture of the sample occurred within the transformed-zone (through a starbranch in $\mathrm{P} 3 \mathrm{~B}$ or through a transformation band in $4 \mathrm{~PB}$ ).

Raman maps in false colour image (Figures 3a and 3b) corroborated that the transformation from the tetragonal to the monoclinic zirconia phase occurred in the optically observed transformed-zones. As shown from the quantitative Raman maps, the highest amount of monoclinic phase ( $\sim 65$ and $\sim 40$ vol. $\%$ for P3B and 4PB respectively) was localized at the centre of the star (Figure 3a) and at the location of fracture ( $x=0$ in Figure $3 b)$. The volume fraction of monoclinic phase along the length $(x)$ of the 4PB sample is also displayed in Figure 3b. Starting from the rupture point, the content of monoclinic phase in adjacent 
bands reached values of around 30 vol. $\%$ and then decreased to 20 vol.\% moving away from the failure point. Consequently, the overall transformation degree on 4PB tested sample seems to be partial (i.e. only 20 to $30 \%$ of the grains are transformed inside transformed zones).

\subsection{Ductile mechanical behaviour}

A typical four-point bending (4PB) load/unload stress-strain curve obtained from $\mathrm{ZA}_{8} \mathrm{Sr}_{8} \mathrm{Ce}_{11}$ material is shown in Figure 4a. The stress was calculated following equation (5) (ISO 6872).

$$
\sigma=\frac{3}{2} F \frac{(L-l)}{b h^{2}}
$$

where, $F$ is the applied load, $L$ and $l$ the outer and inner spans lengths, $b$ the sample's width and $h$ its thickness. The strain was estimated from LVDT data after correcting for the elastic contribution (deformation) of the fixture. Clearly, an elastic-plastic behaviour is observed with a significant strain to failure $(0.38 \%)$ and the deviation from the elastic behaviour started at a stress of $417 \mathrm{MPa}$ (Figure 4a). The evolution of the Young's modulus $(E)$, estimated from loading/unloading slopes, is presented in Figure $4 \mathrm{~b}$. The Young's modulus remained practically constant as the strain increased with a mean value of $214 \pm 4 \mathrm{GPa}$, in agreement with previous results on the same material's composition and chemistry [35].

Young's modulus values measured by resonant frequency method and summarized in Table 1, were the same on both non-tested and 4PB bars loaded up to $95 \%$ of the failure load

\subsection{X-ray RefractionTopography (XRRT) characterization of P3B tested sample}

The 2D refraction topographs obtained at $0^{\circ}$ and $90^{\circ}$ are shown in Figure 5a. The refraction values $\left(\mathrm{C}_{\mathrm{m}}\right)$ and the linear absorption coefficients $(\mu)$ were directly extracted from the refracted and transmitted intensity data, and the calculated ratio $C_{\mathrm{m}} / \mu$ along the indicated red arrows and mean values in transformed (centre of the disc) and untransformed (outer edge of the disc) regions are shown in Figures $5 \mathrm{~b}$ and $5 \mathrm{c}$, respectively. We observe that the normalized refraction values are almost the same in the two perpendicular orientations and in the two regions (transformed and intact). Indeed, the grey levels and the line profiles (Figures $5 \mathrm{a}$ and $5 \mathrm{~b}$ respectively), are comparable in transformed and non-transformed regions, regardless of the orientation. All differences are well within the uncertainty of the measurement.

\subsection{Microscopic features of transformed-zones in P3B and $4 P B$}


The SEM characterization of the tensile surface in P3B tested samples shows transformed monoclinic zirconia grains characterized by different grey levels in the shape of "twins", showing a typical stack of self-accommodating martensitic variant pairs (Figure 6). Very few microcracks were observed at the surface of transformed zones, even near the breaking point.

Inside a 4PB band, SEM characterization of the FIB-prepared TEM foil (Figure 7) shows transformed zirconia monoclinic grains with visible monoclinic laths (m-laths), indicative of twins. The absence of both microcracks and debonding between the different phases inside the analysed transformation band was established at the SEM scale. Only at the top surface of the foil very few microcracks were observed, typically limited to the first layer of grains (less than $1 \mu \mathrm{m}$ depth) as shown in Figures 7 .

On a smaller scale, Figure 8 displays the TEM images obtained on the same thin-foil. Transformed zirconia grains showing monoclinic laths can be seen (clearly visible Figure 8f). Aluminate grains appeared deformed (dislocation like contrast or Bragg's fringes as revealed by the grey lines in Figure 8c). This behavior is related to the high compressive stresses around these grains due to the volume expansion resulting from $t-m$ phase transformation of the surrounding monoclinic grains. This behavior was also clearly observed in a $12 \mathrm{~mol} \% \mathrm{Ce}-$ TZP ceramic [50]. As for the SEM observations, neither micro/nanocracks nor debonding between the different phases were detected inside the transformation band by TEM (Figures 8e and 8f).

\section{Discussion}

The first transformed regions in $\mathrm{P} 3 \mathrm{~B}$ and $4 \mathrm{~PB}$ tested samples were clearly visible at stress values between 355 to $432 \mathrm{MPa}$ (Figure 2). The onset of the non-linear stress-strain behaviour coincided well with the development of the first zirconia $t-m$ transformation bands on the tensile surfaces of 4PB bars (417 MPa) (Figure 4). The increase of the transformedzones area was also related to an increased plastic strain. Therefore, the relatively large strain before failure $(0.38 \%$ in $4 \mathrm{~PB}, 0.55 \%$ in $\mathrm{P} 3 \mathrm{~B}$ [41]) can be related to the stress-induced zirconia $t-m$ phase transformation, as already reported for Ce-TZP composites with similar composition and/or microstructural features [34-38, 41, 42]. A minor contribution of dislocation plasticity (of strontium aluminate, see Figure 8) to the global $\mathrm{ZA}_{8} \mathrm{Sr}_{8} \mathrm{Ce}_{11}$ strain may be expected. However, this effect is considered to be very minor and not significant compared to the $t-m$ phase transformation since, as discussed later in this section, the global 
$\mathrm{ZA}_{8} \mathrm{Sr}_{8} \mathrm{Ce}_{11}$ strain can be completely recovered by heating deformed samples to a temperature above the reverse $\mathrm{T}_{\mathrm{m}-\mathrm{t}}$ temperature.

The $\mathrm{ZA}_{8} \mathrm{Sr}_{8} \mathrm{Ce}_{11}$ composite clearly shows a high transformability and its strength is therefore limited by the critical stress necessary to induce the tetragonal to monoclinic zirconia phase transformation $\left({\sigma_{c}}^{t-m}\right)$, as proposed by Swain and Rose [18] and other authors $[42,65]$. Basically:

$$
\sigma_{\max } \cong \sigma_{y} \cong \sigma_{c}^{t-m}
$$

Where $\sigma_{\max }$ is the maximum strength, $\sigma_{y}$ the yield strength and $\sigma_{c}^{t-m}$ the critical stress to induce the $t-m$ phase transformation.

Hence, the measured value of $\sigma=417 \mathrm{MPa}$ could be considered as the yield transformation stress $\left(\sigma_{y}\right)$ of the $4 \mathrm{~PB}$ tested $\mathrm{ZA}_{8} \mathrm{Sr}_{8} \mathrm{Ce}_{11}$ composite. This value is consistent with most estimates from other works [35, 41], even though the 4PB strength (about 600 $\mathrm{MPa}$ ) still remains considerably lower when compared with that of 3Y-TZP ( $>1 \mathrm{GPa})$ [66]. Overall, in the present case the maximum strength values are overestimated in 4PB and $\mathrm{P} 3 \mathrm{~B}$, as a purely linear elastic behaviour was considered for the strength determination (i.e. as soon as the onset of plasticity is reached, the calculated stresses are overestimated and this effect becomes more and more pronounced as the load is increased). It is important to note also that as the $\mathrm{ZA}_{8} \mathrm{Sr}_{8} \mathrm{Ce}_{11}$ strength is highly dependent upon the testing method [41], P3B test yielded higher transformation stress $(>500 \mathrm{MPa})$, higher strength $(>1 \mathrm{GPa})$ and higher rupture strain ( $\sim 0.55 \%[41])$ compared to $4 \mathrm{~PB}$ test.

Considering the loading/unloading curves (Figure 4a), typical hysteresis loops are visible. During the first cycles (calculated plastic strain $<0.1 \%$ ), a limited hysteresis is obtained and loading and unloading curves are superimposing, indicating an absence of recovery or dissipation. Interestingly, as the sample was reloaded, precisely the same stress and strain were reached before further plastic straining, indicating also an absence of time dependency and in agreement with an absence of recovery or damage. However, as the plastic strain was further increased ( $>0.1 \%$ ), a slight opening of the hysteresis loops was visible, which could either be a sign of microcracking, reverse phase transformation or twinning phenomena [67].

Estimated (from stress-strain curves) and measured Young's moduli are reported in Figure $4 \mathrm{~b}$ and Table 1 . The relatively constant value of the Young's modulus as the number of loading/unloading cycles increased (and therefore cumulated strain) is assume to be a good evidence of the absence of damage accumulation. Moreover, accurate ultrasound resonance vibration measurements further confirmed that no change of $E$ occurred in permanently 
deformed samples with respect to non-tested ones (Table 1). These results are in perfect agreement with previous works that show no significant variations of the Young's modulus in the plastic region, when testing by loading/unloading (4PB) either a 9 mol\% Ce-TZP materials [36], or another material with a comparable composition to the present one [35]. The results obtained at $95 \%$ of the failure load (about $214 \mathrm{GPa}$ from the slope analysis and 215 GPa by Grindo-Sonic) are comparable and in agreement with previous results on similar systems $[35,41]$.

From the microstructural point of view, both microscopy and X-ray refraction techniques showed that neither micro- nor nanocracks or phase debonding were evident inside transformed zones (Figures 5 to 7). The very few microcracks observed at the top surface of a thin slice could be partially explained by a possible relaxation of the substantial internal stresses [68] during the FIB cutting process. However, such microcracks were also observed at the surface of tested but uncut specimens after P3B and 4PB (Figure 6). They were always located inside transformation bands, whereas no microcracks on the upper surface were visible outside the transformation bands. These few microcracks seem therefore directly related to the $t-m$ transformation as they are present only at the very top surface of a transformed zone (i.e. the first grains only, see Figure 8) without affecting the overall mechanical strength of the material. However, further investigation on the influence of such cracks on the fatigue resistance of the material should be performed to confirm such a statement.

A decrease in the Young's modulus as a function of strain is often associated with microcracking and damage accumulation in ceramics [69]. This evolution of damage can be described by simple micromechanical models, as for example the Differential Scheme [70-72]. The model takes the microgeometry of the materials into account for estimating the effect of pores and cracks on the elastic moduli. The microcrack density parameter $\rho$ of a system of penny-shaped cracks equivalent to those present in the material can be estimated by the relation (7):

$$
\frac{E}{E_{0}}=e^{-C \rho}
$$

Where $E$ and $E_{0}$ are the Young's moduli of the microcracked and intact materials, and $C$ is a constant $\left(C=\frac{16 \cdot\left(1-v^{2}\right) \cdot(10-3 v)}{45 \cdot(2-v)}=1.64\right.$ for $v=0.25$, as referred to [70]). Equation (8) yields the change of microcrack density with respect to the initial state as:

$$
\Delta \rho=\frac{1}{C} \cdot \ln \left(\frac{E_{0}}{E}\right)
$$


Using our data, we would obtain a decrease of less than $5 \%$ of the unloading Young's modulus, leading to $\Delta \rho<1-10 \times 10^{-3}$ which is much smaller than typical values for microcracked materials [71, 73-77]. Taking the Young's modulus measured upon loading, this would lead to a negligible variation. This result is in agreement with an absence of extensive microcrack damage related to the $t-m$ phase transformation, as corroborated by SEM/TEM and XRRT analyses. Furthermore, this very small Young's modulus variation could possibly be related to the assumption the $m$ zirconia exhibits a lower stiffness than that of the $t$ phase (even though this fact has not yet been demonstrated experimentally or numerically).

SEM/TEM images show that the transformation zone deeper than 1 micron from the surface does not exhibit microcracks, as it was concluded in other works done on Mg-PSZ [45]. The mechanical behaviour of $\mathrm{ZA}_{8} \mathrm{Sr}_{8} \mathrm{Ce}_{11}$ composite can therefore be considered as almost purely elastic-plastic (i.e. not significantly affected by damage). In other words, the plasticity is essentially driven by the stress-induced $t-m$ transformation with negligible internal damage. This result is of primary interest as it elucidates that the transformation is the mechanism responsible for the plasticity of the ceramic composite. Indeed, unlike other zirconia-based systems [42-46] the transformation is not detrimental for the reliability of such material under operating conditions or in-vivo, as the overall mechanical properties (exemplified by the Young's modulus) remain intact. The transformation will even act as a toughening mechanism as it promotes unprecedented ductility for a ceramic material [78].

As expected, Raman analyses have shown an increase of the monoclinic $\mathrm{ZrO}_{2}$ content inside the transformation bands (4PB) or star-like branches (P3B). This is in accordance with previous observations made on the characterization of Ce-TZP ceramics [40], where the hypothesis was advanced that an autocatalytic phase transformation was taking place, with the formation of transformation bands leading to a strongly inhomogeneous and localized distribution of the monoclinic phase. In other study, R. Rauchs et al. [38] have found an average monoclinic fraction between 40 to $60 \mathrm{vol} \%$ perpendicular to individual $4 \mathrm{~PB}$ transformation bands. This amount varies from one sample to another and was directly related to the grain size and therefore the transformability of tested materials. The higher the amount of monoclinic phase the larger the grain size (and therefore the ease of transformability). For example, they measured a monoclinic volume fraction of $40 \%$ for Ce-TZP grains of $1.4 \mu \mathrm{m}$. This value cannot be compared directly to the value of 20-30 vol.\% obtained in this study as we have a different microstructure (with alumina and aluminates as second and third phase) and a smaller zirconia grain size $(0.9 \mu \mathrm{m})$. However, the magnitude of the transformation 
between these reported values and those presented here is comparable. Additionally, Rauchs

et al. [79] have also reported that the monoclinic phase content along the diameter of a 9 mol.\% Ce-TZP specimen ( $0.9 \mu \mathrm{m}$ grain size) tested in biaxial bending ranged between 10 to $14 \%$ whereas along the length axis of a $4 \mathrm{~PB}$ test bar it ranged from 7 to $10 \%$. This is again in agreement with the fact that only a part of the tetragonal grains is transformed inside transformation features and that the material's behavior is a function of the test method (more specifically on the homogeneity of the stress field, or lack thereof), with much more transformation (and larger transformed zone) when the stress field is inhomogeneous and localized (P3B), compared to less important transformation features (thin parallel bands) when the stress field is more homogeneous (4PB) [41]. In another study, Gogotsi et al. [36] mentioned that, after bending tests on Ce-TZP ceramics, not all the grains were transformed and that this amount was lower than 65 vol.\%. This is also in good agreement with Raman spectroscopy measurements performed on Ce-TZP transformed-bands by Becher and Swain [80] on ceramics with larger grain sizes (from 1.3 to $8 \mu \mathrm{m}$ ). An increase of the measured fraction of monoclinic $\mathrm{ZrO}_{2}$ was also observed inside transformation bands as the grain size (and therefore the transformability) was increased. Grathwohl and Liu [81] also compared the monoclinic phase content at the tensile surface of different 9 mol.\% Ce-TZP ceramics with different grain sizes after various mechanical tests. They showed that monoclinic contents ranged between 5 to $27 \%$ depending on the testing procedure and the materials' grain size. They also found that cyclic loading leads to enhanced phase transformation compared to static loading or short term loading to higher stress levels. And this was found to be even more pronounced for larger grain size samples. The results of these studies are in good agreement with our findings.

From Raman analyses, the highest amount of monoclinic phase in $4 \mathrm{~PB}$ is to be found at the point of failure, localized at $\mathrm{x}=0$ ( $\sim 43$ vol.\%) (Figure $3 \mathrm{~b})$, indicating that excessive localization of the transformation indeed leads to failure at this point. In P3B tested samples, the highest content of monoclinic phase is located just under the piston ( $\sim 65 \mathrm{vol} \%$ ), as the transformation pattern is strongly related to the stress field; again, failure takes place along the transformed material (Figure 3a). The location of the breakage is consistent with the material's behaviour; i.e. failure should occur in a zone that has already transformed and no longer has the capability to accommodate a stress increase by yielding (via phase transformation).

X-ray refraction topography (XRRT) provided further evidence of the absence of microcracks and damage associated with transformation. In fact, microcracks having an aperture as small 
as $1 \mathrm{~nm}$ may be detected by X-ray refraction techniques [53, 82, 83]. However, the results of the quantitative analysis of XRRT data showed that the quantity of internal specific surfaces in $\mathrm{ZA}_{8} \mathrm{Sr}_{8} \mathrm{Ce}_{11}$ was the same for transformed and non-transformed zones (Figure 5), indicating that negligible damage was produced during the $t-m$ phase transformation. Analogous to visible-light, X-ray refraction occurs when X-rays pass through interfaces of media with different densities or refractive indices. This effect will be significant at for example; solid-solid interfaces with different refractive indices (organic fibers-ceramic matrix interfaces) and solid-gas interfaces (fiber-debonding, porosity or microcracks). In our case, the $t-m$ zirconia interfaces created during the deformation do not affect significantly the X-ray refraction effect ( $t$ and $m$ have similar densities and refractive indices) and the normalized refraction value remains stable, corroborating the absence of microcracking.

The overall results suggest that the transformation induced plasticity of the studied Ce-TZP composite is not associated with microcracking and associated damage. Moreover, thermal annealing $\left(1200^{\circ} \mathrm{C}-30 \mathrm{~min}\right)$ of $4 \mathrm{~PB}$ bars initially loaded beyond the yield stress and unloaded exhibit complete recovery of the inelastic deflection due to the $m-t$ transformation (not shown here). Although this effect has been investigated in 4PB bars, it suggests that shear and dilation associated with the $t-m$ transformation can be elastically and plastically accommodated without microcracking or substantial dislocation motion. This shape memory effect has been previously observed in zirconia ceramics $[\mathbf{8 4}, \mathbf{8 5}]$ and associated to the martensitic transformation but was usually also associated with microcracking [42-44]. The current materials show that microcracking phenomenon has been suppressed by their finescale microstructure with few crystal grains in the shape of pillars (oligocrystalline structures) that reduced internal mismatch stresses associated with transformation thanks to the size of grain boundaries [86]. Our results also show that microcracking induced by the transformation can be suppressed in polycrystalline ceramics if the grain size of zirconia is reduced. The shape-memory alloy properties of polycrystalline ZA8Sr8Ce11 will be extensively discussed in an upcoming publication.

\section{Conclusions}

The $\mathrm{ZA}_{8} \mathrm{Sr}_{8} \mathrm{Ce}_{11}$ composite under study showed transformation-induced plasticity with a significant plastic strain at failure $(\sim 0.38 \%)$ and a critical stress to induce the $t$ - $m$ phase transformation of $\sim 400 \mathrm{MPa}$ in $4 \mathrm{~PB}$. The $t-m$ transformation was visible on $4 \mathrm{~PB}$ samples in the shape of dispersed parallel bands. The monoclinic amount inside transformation bands ranged from $\sim 45$ vol.\% (fracture) to $20-30$ vol.\% (other adjacent bands). Therefore, the 
composite exhibited a relatively limited amount of $t-m$ phase transformation, in agreement with previous studies on similar materials.

Both SEM and TEM characterization have shown the presence of transformed zirconia monoclinic grains in the form of visible $m$-laths. Moreover, both SEM and TEM analyses have shown the absence of either microcracks/nanocracks or phase debonding inside transformed bands, except in the close proximity of the external surface, where plane stress conditions are met. Finally, X-ray refraction analyses performed on P3B tested samples unequivocally demonstrated that the developed $\mathrm{ZA}_{8} \mathrm{Sr}_{8} \mathrm{Ce}_{11}$ material present no damage accumulation, even at failure.

The key point of our work was the preparation of composites based on Ce-TZP zirconia with the aim of reducing the zirconia grain size, improving the strength and allowing relatively high deformation at failure without damage. Although much more work remains to fully understand the behavior of these materials, especially under cyclic conditions, the unusual transformation plasticity without damage reported here may re-open the discussion on Ce-stabilized zirconia as an engineering ductile material more than 40 years after the concept of "ceramic steel".

\section{Funding}

This research was undertaken in the framework of the LONGLIFE project (http://www.longlife-project.eu) funded by the European Community's Seventh Framework Program (FP7/2007-2013) [grant agreement n. 280741] and the SISCERA project (http://siscera-project.eu) also funded by E.U. (H2020-FTIPilot-2016), [grant agreement $\mathrm{n}$. 737954].

\section{Acknowledgments}

We thank colleagues from Politecnico di Torino, Marta Fornabaio, Paola Palmero, Laura Montanaro, who participate to the development of composite materials. We also deeply thank Yunheng Yu, Arnaud Doko, and Christian Olagnon, who took part on some different steps of preliminary mechanical tests. We acknowledge the CLYM (Centre Lyonnais de Microscopie), supported by the CNRS, the "Grand Lyon" and the Rhône-Alpes Region for the access to the FIB/SEM device used in this study. Pietro Tassan and Piero Gherbaz are acknowledged for collecting some of the Raman data. 


\section{References}

[1] A.G. Evans, A.H. Heuer, Review-transformation toughening in ceramics: martensitic transformations in crack-tip stress fields, J. Am. Ceram. Soc. 63 (1980) 241-248.

[2] R.H.J. Hannink, P.M. Kelly, B.C. Muddle, Transformation toughening in zirconia containing ceramics, J. Am. Ceram. Soc. 83 (2000) 461-487.

[3] J. Chevalier, B. Cales, J.M. Drouin, Low-temperature aging of Y-TZP ceramics, J. Am. Ceram. Soc. 82 (1999) 2150-2154.

[4] S. Deville, J. Chevalier, L. Gremillard, Influence of surface finish and residual stresses on the ageing sensitivity of biomedical grade zirconia, Biomaterials. 27 (2006) 2186-2192.

[5] J. Chevalier, L. Gremillard, S. Deville, Low-Temperature Degradation of Zirconia and Implications for Biomedical Implants, Annu. Rev. Mater. Res. 37 (2007) 1-32.

[6] J. Chevalier, L. Gremillard, A. V. Virkar, and D. R. Clarke, The tetragonal-monoclinic transformation in zirconia: Lessons learned and future trends, J. Am. Ceram. Soc. 92 (2009), 1901-1920.

[7] M.J. Lance, E.M. Vogel, L.A. Reith, W.R. Cannon, Low-temperature aging of zirconia ferrules for optical connectors, J. Am. Ceram. Soc. 84 (2001) 2731- 2733.

[8] I.M. Ross, W.M. Rainforth, D.W. McComb, A.J. Scott, R. Brydson, The role of trace additions of alumina to yttria-tetragonal zirconia polycrystals (Y-TZP), Scripta Mater. 45 (2001) 653-660.

[9] F.F. Lange, Transformation toughening I. Size effects associated with the thermodynamics of constrained transformations, J. Mater. Sci. 17 (1982) 225- 234.

[10] L. Hallmann, The influence of grain size on low-temperature degradation of dental zirconia, J. Biomed. Mater. Res. B Appl. Biomater. 100 (2012) 447-456.

[11] F. Zhang, K. Vanmeensel, M. Inokoshi, M. Batuk, J. Hadermann, B. Van Meerbeek, I. Naert, J. Vleugels, 3Y-TZP ceramics with improved hydrothermal degradation resistance and fracture toughness, J. Eur. Ceram. Soc. 34 (2014) 2453-2463.

[12] F. Zhang, K. Vanmeensel, M. Batuk, J. Hadermann, M. Inokoshi, B. Van Meerbeek, I. Naert, J. Vleugels, Highly-translucent, strong and aging-resistant 3Y-TZP ceramics for dental restoration by grain boundary segregation, Acta Biomater.16 (2015) 215-222.

[13] I. Tredici, M. Sebastiani, F. Massimi, E. Bemporad, A. Resmini, G. Merlati, U. AnselmiTamburini, Low temperature degradation resistant nanostructured yttria-stabilized zirconia for dental applications, Ceram. Int.42(2016) 8190-8197.

[14] V. Lughi, V. Sergo, Low temperature degradation -aging- of zirconia: a critical review of the relevant aspects in dentistry, Dent. Mater. 26 (2010) 807-820. 
[15] P. Kohorst, L. Borchers, J. Strempel, M. Stiesch, T. Hassel, F.W. Bach, C. Hübsch, Lowtemperature degradation of different zirconia ceramics for dental applications, Acta Biomater. 8 (2012) 1213-1220.

[16] K. Tsukuma, M. Shimada, Strength, fracture toughness and Vickers hardness of $\mathrm{CeO}_{2}-$ stabilized tetragonal $\mathrm{ZrO}_{2}$ polycrystals (Ce-TZP), J. Mater. Sci. 20 (1985) 1178-1184.

[17] H. El Attaoui, M. Saâdaoui, J. Chevalier, G. Fantozzi, Static and cyclic crack propagation in Ce-TZP ceramics with different amounts of transformation toughening, J. Eur. Ceram. Soc. 27 (2007) 483-486.

[18] M. V. Swain, L. R. F. Rose, Strength Limitations of Transformation-Toughened Zirconia Alloys, J. Am. Ceram. Soc. 69 (1986) 511-518.

[19] T. Sato, T. Endo, M. Shimada, Postsintering hot isostatic pressing of ceria-doped tetragonal zirconia/alumina composites in an argon-oxygen gas atmosphere, J. Am. Ceram. Soc. 72 (1989) 761-764.

[20] J.F. Tsai, C.S. Yu, D.K. Shetty, Fatigue crack propagation in ceria-partially- stabilized zirconia (Ce-TZP)-alumina composites, J. Am. Ceram. Soc. 73 (1990) 2292-3001.

[21] C.S. Yu, D.K. Shetty, M.C. Shaw, D.B. Marshall, Transformation zone shape effects on crack shielding in ceria-partially-stabilized zirconia (Ce-TZP)-alumina composites, J. Am. Ceram. Soc. 75 (1992) 2991-2994.

[22] H.K. Schmid, R. Pennefather, S. Meriani, C. Schmid, Redistribution of Ce and La during processing of $\mathrm{Ce}(\mathrm{La})-\mathrm{TZP} / \mathrm{Al}_{2} \mathrm{O}_{3}$ composites, J. Eur. Ceram. Soc. 72 (1992) 761-764.

[23] M. Nawa, S. Nakamoto, T. Sekino, K. Niihara, Tough and strong Ce-TZP/Alumina nanocomposites doped with Titania, Ceram. Int. 10 (1998) 381-392.

[24] R. Benzaid, J. Chevalier, M. Saâdaoui, G. Fantozzi, M. Nawa, L.A. Diaz, Slow-crack propagation behavior in Ce-TZP/ $/ \mathrm{Al}_{2} \mathrm{O}_{3}$ nanocomposites, Biomaterials 29 (2008) 1560-1565.

[25] K. Morita, K. Hiraga, B.N. Kim, H. Yoshida, Y. Sakka, Synthesis of dense nanoscrystalline $\mathrm{ZrO}_{2}-\mathrm{MgAl}_{2} \mathrm{O}_{4}$ spinel composite, Scr. Mater. 53 (2005) 1007-1012.

[26] E. Apel, C. Ritzberger, N. Courtois, H. Reveron, J. Chevalier, M. Schweiger, F. Rothbrust, V.M. Rheinberger, W. Höland, Introduction to a tough, strong and stable Ce$\mathrm{TZP} / \mathrm{MgAl}_{2} \mathrm{O}_{4}$ composite for biomedical applications, J. Eur. Ceram. Soc. 32 (2012) 26972703.

[27] R.A. Cutler, R.J. Mayhew, K.M. Prettyman, A.V. Virkar, High-toughness Ce-TZP/ $\mathrm{Al}_{2} \mathrm{O}_{3}$ ceramics with improved hardness and strength, J. Am. Ceram. Soc. 74 (1991) 179-186. [28] M. Miura, H. Hongoh, T. Yogo, S. Hirano, T. Fujll, Formation of plate-like lanthanum- $\beta-$ aluminate crystal in Ce-TZP matrix, J. Mater. Sci. 29 (1994) 262-268. 
[29] S. Maschio, G. Pezzotti, O. Sbaizero, Effect of $\mathrm{LaNbO}_{4}$ addition on the mechanical properties of ceria-tetragonal zirconia polycrystal matrices, J. Eur. Ceram. Soc. 18 (1998) 1779-1785.

[30] S. Ori, T. Kojima, T. Hara, N. Uekawa, K. Kakegawa, Fabrication of Ce-TZP/bhexaaluminate composites using amorphous precursor of the second phase, J. Ceram. Soc. Jpn. 120 (2012) 111-115.

[31] T. Yamaguchi, W. Sakamoto, T. Yogo, T. Fujii, S. Hirano, In situ formation of CeTZP/Ba-hexaaluminate composites, J. Ceram. Soc. Jpn. 107 (1999) 814-916.

[32] F. Kern, A comparison of microstructure and mechanical properties of 12Ce- TZP reinforced with alumina and in situ formed strontium- or lanthanum- hexaaluminate precipitates, J. Eur. Ceram. Soc. 34 (2014) 413-423.

[33] M. Lambrigger, Evaluation of Weibull master curves of zirconia ceramics and zirconia/alumina composites, J. Mater. Sci. Lett. 16 (1997) 924-926.

[34] P. Palmero, M. Fornabaio, L. Montanaro, H. Reveron, C. Esnouf, J. Chevalier, Towards long lasting zirconia-based composites for dental implants. Part I: Innovative synthesis, microstructural characterization and in vitro stability, Biomaterials, 50 (2015) 38-46.

[35] H. Reveron, M. Fornabaio, P. Palmero, T. Fürderer, E. Adolfsson, V. Lughi, A. Bonifacio, V. Sergo, L. Montanaro, J. Chevalier, Towards long lasting zirconia-based composites for dental implants: Transformation induced plasticity and its consequence on ceramic reliability, Acta Biomater. 48 (2017) 423-432.

[36] G. A. Gogotsi, V. P. Zavada, and M. V Swain, Mechanical Property Characterization of a 9 mol\% Ce-TZP Ceramic Material -I. Flexural Response, J. Eur. Ceram. Soc. 15 (1995) $1185-1192$.

[37] G. Grathwohl and T. Liu, Crack Resistance and Fatigue of Transforming Ceramics: I, Materials in the $\mathrm{ZrO}_{2}-\mathrm{Y}_{2} \mathrm{O}_{3}-\mathrm{Al}_{2} \mathrm{O}_{3}$ System, J. Am. Ceram. Soc. 34 (1991) 318-325.

[38] G. Rauchs, T. Fett, D. Munz, and R. Oberacker, Tetragonal-to-monoclinic phase transformation in $\mathrm{CeO}_{2}$-stabilised zirconia under uniaxial loading, J. Eur. Ceram. Soc., 21 (2001) 2229-2241.

[39] R. C. Garvie, R.H.J. Hannink, R.T. Pascoe,’Ceramic steel?”, Nature, 258 (1975) 703-704. [40] R.H.J. Hannink, M. V. Swain, Metastability of the Martensitic Transformation in a 12 mol\% Ceria-Zirconia Alloy: I, Deformation and Fracture Observations, J. Am. Ceram. Soc. 72 (1989) 90-98. 
[41] I. Touaiher, M. Saâdaoui, J. Chevalier, L. Preiss, and H. Reveron, Fracture behavior of

Ce-TZP/alumina/aluminate composites with different amounts of transformation toughening. Influence of the testing methods, J. Eur. Ceram. Soc. 38 (2017) 1778-1789.

[42] S.Y. Liu and I.W. Chen, Fatigue Deformation Mechanisms of Zirconia Ceramics, J. Am. Ceram. Soc. 75 (1992) 1191-1204.

[43] P.E Reyes-Morel, I.W Chen, Stress-Biased Anisotropic Microcracking in Zirconia Polycrystals, J. Am. Ceram. Soc. 73 (1990) 1026-1033.

[44] I.W. Chen, P.E. Reyes-Morel, Implications of Transformation Plasticity in $\mathrm{ZrO}_{2}$ Containing Ceramics: I, Shear and Dilatation Effects, J. Am. Ceram. Soc. 69 (1986) 181-189. [45] J.F. Tsai, D.K. Shetty, Cyclic Fatigue of Ce-TZP/ $/ \mathrm{Al}_{2} \mathrm{O}_{3}$ Composites: Role of the Degradation of Transformation Zone Shielding, J. Am. Ceram. Soc. 78 (1995) 599-608.

[46] J.F. Tsai, J.D. Belnap, D.K. Shetty, Crack Shielding in Ce-TZP/Al $\mathrm{O}_{3}$ Composites: Comparison of fatigue and Sustained Load Crack Growth Specimen, J. Am. Ceram. Soc. 77 (1994) 105-117.

[47] C. Schmid, O. Sbaizero, V. Sergo, S. Meriani, Shape Memory-Like Effect in a CeTZP/Al ${ }_{2} \mathrm{O}_{3}$ Composite, J Am. Ceram. Soc. 75 (1992) 2003-2005.

[48] S. Ban, M. Nawa, F. Sugata, J. Tsuruki, H. Kono, T. Kawai, HRTEM observation of bonding interface between Ce-TZP/ $/ \mathrm{Al}_{2} \mathrm{O}_{3}$ nanocomposite and porcelain, Dent. Mater. J. 33 (2014) 565-569.

[49] E. P. Butler, M. Science, I. College, Transmission electron microscopy of zirconia ceramics, J. Microsc. 140 (1985) 171-182.

[50] M. V Swain, R.H.J. Hannink, Metastability of the Martensitic Transformation in a 12 mol\% Ceria-Zirconia Alloy: II, Grinding Studies, J. Am. Ceram. Soc.n72 (1989) 1358-1364.

[51] K. Matsui, K. Nakamura, A. Kumamoto, H. Yoshida,Y. Ikuhara, Low-temperature degradation in yttria-stabilized tetragonal zirconia polycrystal doped with small amounts of alumina: Effect of grain-boundary energy, J. Eur. Ceram. Soc. 36 (2016) 155-162.

[52] K. Matsui, H. Yoshida, Y. Ikuhara, Nanocrystalline, Ultra-Degradation-Resistant Zirconia: Its Grain Boundary Nanostructure and Nanochemistry, Scientific Reports, 4 (2014) 4758.

[53] A. Kupsch, B.R. Müller, A. Lange, G. Bruno, Microstructure characterisation of ceramics via 2D and 3D X-ray refraction techniques, J. Eur. Ceram. Soc. 37 (2017) 17781889. 
[54] K.W. Harbich, P. Klobes, M.P. Hentschel, Microstructural characterization of porous materials by two-dimensional X-ray refraction topography, Colloids Surf. A. 241 (2004) 225229.

[55] H.V. Rudolph, H.Ivers, K.W. Harbich, Application of X-ray refraction topography to fibre reinforced plastics, Comp.A. 32( 2001) 473-476.

[56] D.E. Mack, R. Laquai, B. Müller, O. Helle, D. Sebold, R. Vaßen, G. Bruno, Evolution of porosity, crack density, and CMAS penetration in thermal barrier coatings subjected to burner rig testing, J. Am. Ceram. Soc. (2019).

[57] R. Laquai, F. Gouraud, B.R. Müller, M. Huger, T. Chotard, G. Antou, G. Bruno, Evolution of thermal microcracking in refractory $\mathrm{ZrO}_{2}-\mathrm{SiO}_{2}$ after application of external loads at high temperatures, Materials, 12 (2019) 1017.

[58] B.R. Müller, R.C. Cooper, A. Lange, A. Kupsch,M. Wheeler, M.P. Hentschel, A. Staude, A. Pandey, A. Shyam, G. Bruno, Stress-induced microcrack density evolution in $\beta$-eucryptite ceramics: Experimental observations and possible route to strain hardening, Acta Mater. 144 (2018) 627-641.

[59] H. Toraya, M. Yoshimura, S. Somiya, Calibration curve for quantitative analysis of the monoclinic-tetragonal $\mathrm{ZrO}_{2}$ system by X-ray diffraction, J. Am. Ceram. Soc. 67 (1984) C119121.

[60] R: A language and environment for statistical computing. R Foundation for Statistical Computin., Vienna, Austria, 2013.

[61] M. Wojdyr. Fityk: a general-purpose peak fitting program, J. Appl. Crystallogr. 43 (2010) 1126-1128.

[62] J.A. Munoz-Tabares, M. Anglada, Quantitative analysis of monoclinic phase in 3Y-TZP by Raman spectroscopy, J. Am. Ceram. Soc. 93 (2010) 1790-1795.

[63] G. Katagiri, H. Ishida, A. Ishitani, T. Masaki, Direct determination by a Raman microprobe of the transformation zone size in $\mathrm{Y}_{2} \mathrm{O}_{3}$ containingtetragonal $\mathrm{ZrO}_{2}$ polycrystals, Adv. Ceram. 24 (1988) 537-544.

[64] J. Chevalier, A. Liens, H. Reveron, F. Zhang, P. Reynaud, T. Douillard, L. Preiss, V. Sergo, V. Lughi, M. Swain, N. Courtois, Fourty years after the promise of « ceramic steel? »: zirconia-based composites with a metal-like mechanical behavior, J. Am. Ceram. Soc. (2019) (submitted)

[65] M.V. Swain, Inelastic deformation of Mg-PSZ and its significance for strength-toughness relationship of zirconia toughened ceramics, Acta Metall. 33 (1985) 2083-2091.

[66] J. Eichler, M. Hoffman, U. Eisele, J. Rödel, R-curve behaviour of 2Y-TZP with 
submicron grain size., J Eur Ceram Soc. 26 (2006) 3575-3582.

[67] S. Y. Liu and I. W. Chen, Plasticity-induced fatigue damage in Ceria-stabilized tetragonal zirconia polycrystlas, J. Am. Ceram. Soc. 77 (1994) 2025-2035.

[68] V. Sergo, D.R. Clarke and W. Pompe, Deformation bands in Ceria-stabilized Zirconia/Alumina: I, Measurement of internal stresses, J. Am. Ceram. Soc. 78 (1995) 633640 .

[69] B.B. Audoin, S.S Baste, Ultrasonic Evaluation of Stiffness Tensor Changes and Associated Anisotropic Damage in a Ceramic Matrix Composite, J. Appl. Mech. 61 (1994) 309-316.

[70] R. McLaughlin, A study of the differential scheme for composite materials, Int. J. Engng. Sci. 15 (1977) 237-244.

[71] R.L. Salganik, Mechanics of bodies with many cracks, Mech. Solids. (1973) 135-143.

[72] G. Bruno, M. Kachanov, On modeling of microstresses and microcracking generated by cooling of polycrystalline porous ceramics, J. Eur. Ceram. Soc. 33 (2013) 1995-2005.

[73] H. Sato, K. Yamada, G. Pezzotti, M. Nawa, S. Ban, Mechanical Properties of Dental Zirconia Ceramics Changed with Sandblasting and Heat Treatment, Dent. Mat. 27 (2008) 408-414

[74] G. Bruno, Y. Kilali, A.M. Efremov, Impact of the non-linear character of the compressive stress-strain curves on thermal and mechanical properties of porous microcracked ceramics, J. Eur. Ceram. Soc. 33 (2013) 211-219

[75] R.C. Cooper, G. Bruno, Y. Onel, A. Lange, T.R. Watkins, A. Shyam, Young's modulus and Poisson's ratio changes due to machining in porous microcracked cordierite, J.Mater.Sci. $51(2016) 9749-9760$

[76] A. Shyam, G. Bruno, T.R. Watkins, A. Pandey, E. Lara-Curzio, C.M. Parish, R.J. Stafford, The effect of porosity and microcracking on the thermomechanical properties of cordierite, J.Eur.Ceram.Soc. 35 (2016) 4557-4566.

[77] G. Bruno, M. Kachanov, I. Sevostianov, A. Shyam, Micromechanical modeling of nonlinear stress-strain behavior of polycrystalline microcracked materials under tension, Acta Mater. 164 (2019) 50-59.

[78] C. Babelot, A. Guignard, M. Huger, C. Gault, T. Chotard, T. Ota, and N.Adachi, Preparation and thermo-mechanical characterization of titanate flexible ceramics, J. Mater. Sci. 45 2011, 1211-19. 
[79] G. Rauchs, T. Fett, D. Munz, R. Oberacker, Tetragonal-to-monoclinic phase transformation in $\mathrm{CeO}_{2}$-stabilized zirconia under multiaxial loading, J. Eur. Ceram. Soc., 2002, 841-849.

[80] P. F. Becher, M. V Swain, Grain-Size-Dependent Transformation Behavior in Polycrystalline Tetragonal Zirconia, J. Am. Ceram. Soc. 75 (1992) 493-502.

[81] G. Grathwohl and T. Liu, Crack Resistance and Fatigue of Transforming Ceramics: II, $\mathrm{CeO}_{2}$-stabilized tetragonal $\mathrm{ZrO}_{2}$, J. Am. Ceram. Soc. 1991, 3028-3034.

[82] M.P. Hentschel, R. Hosemann, A. Lange, B. Uther, R. Bruckner, Small-angle X-ray refraction in metal wires, glass-fibers and hard elastic propylenes, Acta. Crystallogr. 43 (1987) 506-513.

[83] S. Cabeza, B. R. Müller, R. Pereyra, R. Fernández, G. González-Doncel, G. Bruno, Evidence of damage evolution during creep of $\mathrm{Al}-\mathrm{Mg}$ alloy using synchrotron X-ray refraction. J .App. Cryst. 51( 2018) 420-427.

[84] M.V. Swain, Shape memory behaviour in partially stabilized zirconia ceramics, Nature 322 (1986) 234-236.

[85] P.E. Reyes-Morel, J-S Cherng, I.W. Chen, Transformation Plasticity of $\mathrm{CeO}_{2}-\mathrm{Stabilized}$ Tetragonal Zirconia Polycristals: II. Pseudoplasticity and Shape Memory Effect, J. Am. Ceram. Soc. 71 (1988) 648-657.

[86] A. Lai, Z. Du, C.L. Gan, C.A. Schuh, Shape Memory and Superplastic Ceramics at Small Scales, Science 341 (2013) 1505-1508. 

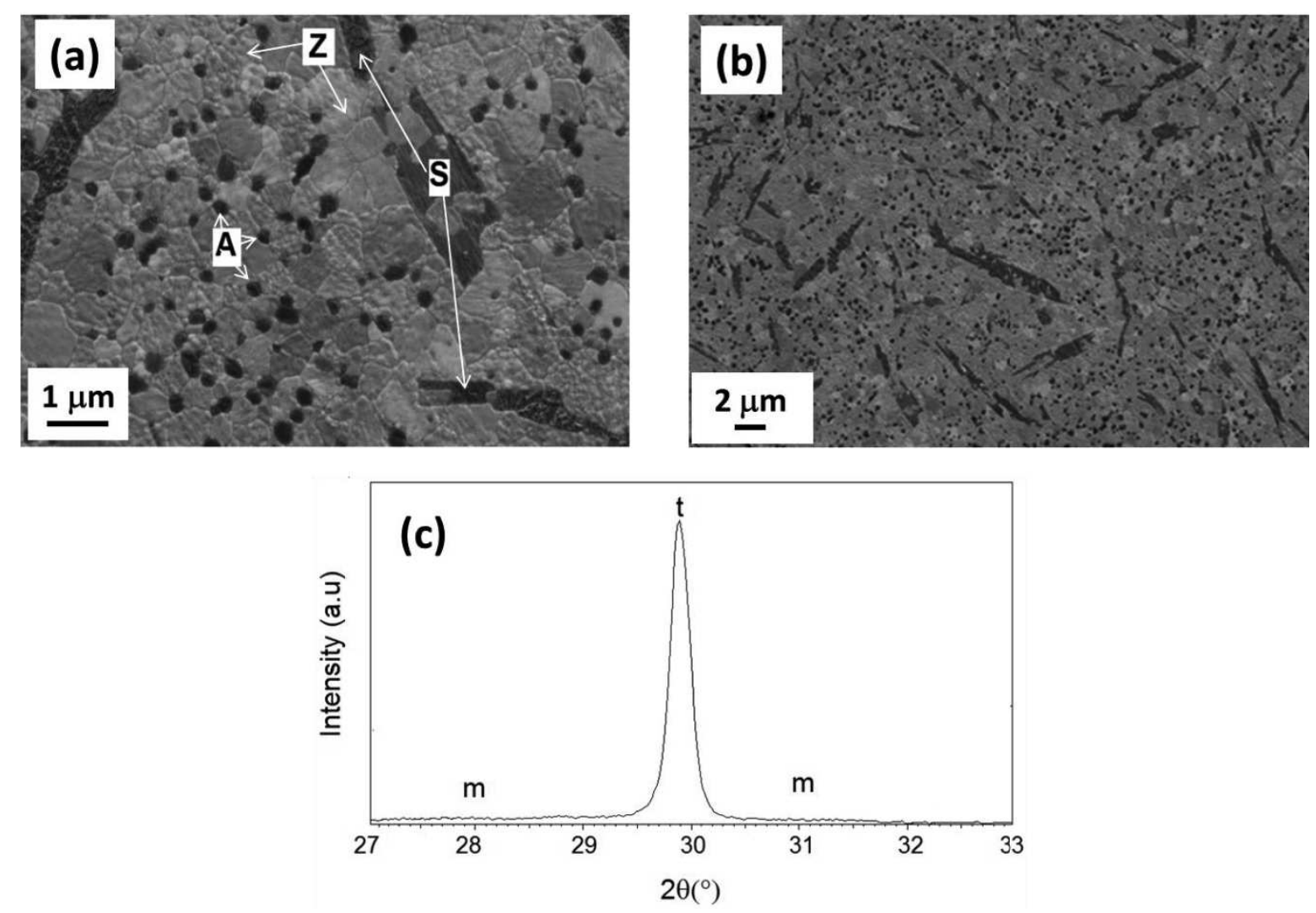

Figure 1. $(\mathrm{a}, \mathrm{b})$ Microstructural features of the $\mathrm{ZA}_{8} \mathrm{Sr}_{8} \mathrm{Ce}_{11}$ composite (SEM imaging after polishing and thermal etching at $1350^{\circ} \mathrm{C}-20 \mathrm{~min}$; Z: Zirconia, A: Alumina and S: Strontium Aluminate). (c) XRD pattern in the $2 \theta$ region of $27-33^{\circ}$, where the peaks for $(111)_{\mathrm{m}},(-111)_{\mathrm{m}}$ and (101)t of zirconia should appear, clearly indicating that zirconia is fully tetragonal. The XRD analyzed region $\left(2 \theta=27-33^{\circ}\right)$ does not include diffraction peaks for alumina (JCPDS $\mathrm{N}^{\circ}$ 46-1212). The aluminate phase contains two peaks $\left(2 \theta=31.99^{\circ}\right.$ and $32.41^{\circ} ; 55 \%$ and $20 \%$ of intensity-JCPDS $\mathrm{N}^{\circ}$ 26-0976) but due to the difference in the absorption coefficients, the relative intensity associated to these peaks and the low phase volume content ( $8 \mathrm{vol} . \%)$, they are undetectable. 

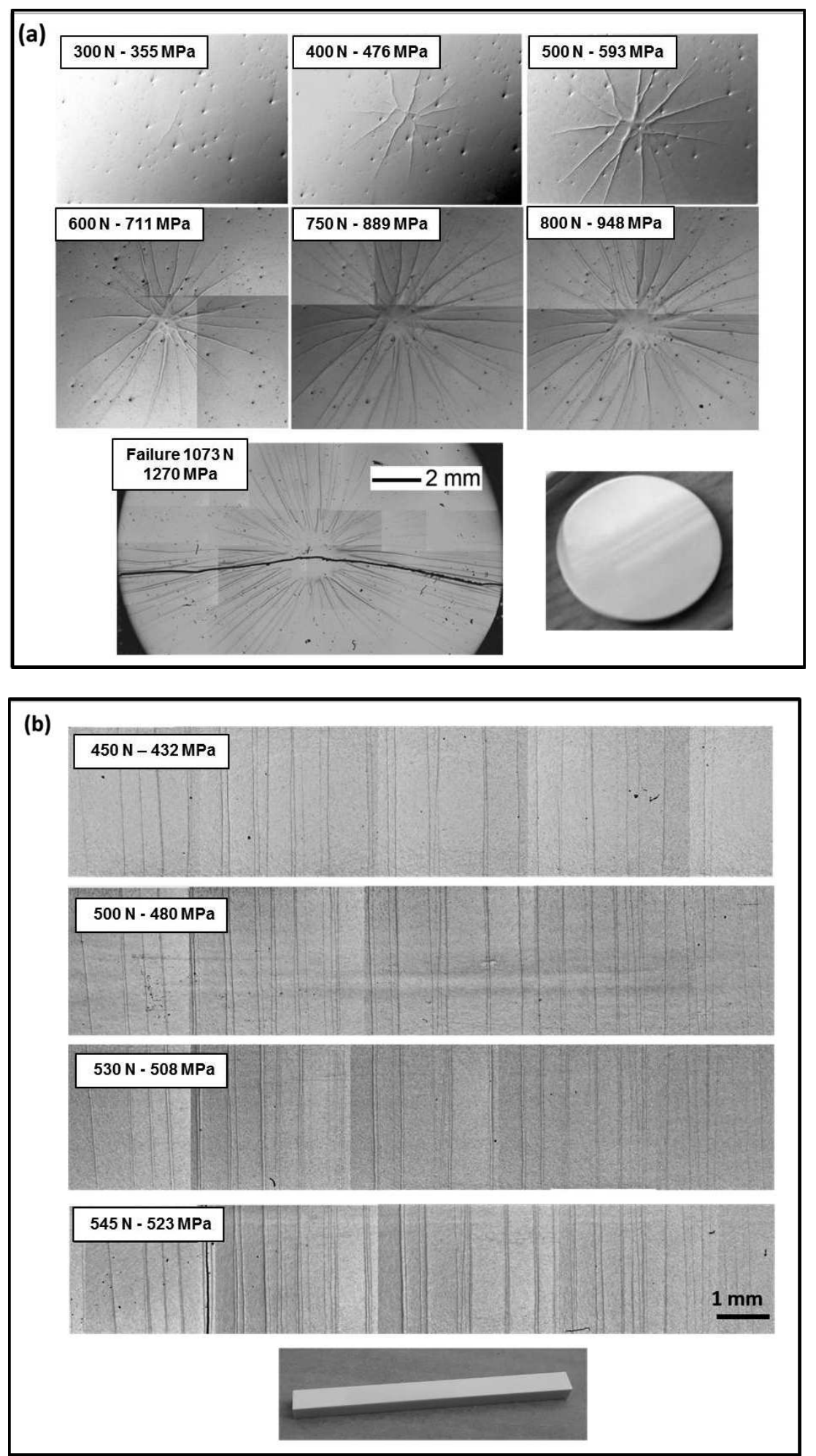

Figure 2. Optical characterization of transformed zones on (a) biaxial P3B and (b) 4PB samples showing star-like phase transformation and parallel transformed bands respectively. The inset in each image represents the load and the calculated stress to which the samples have been subjected. Both in (a) and (b) the last image is a photograph of the entire sample. 


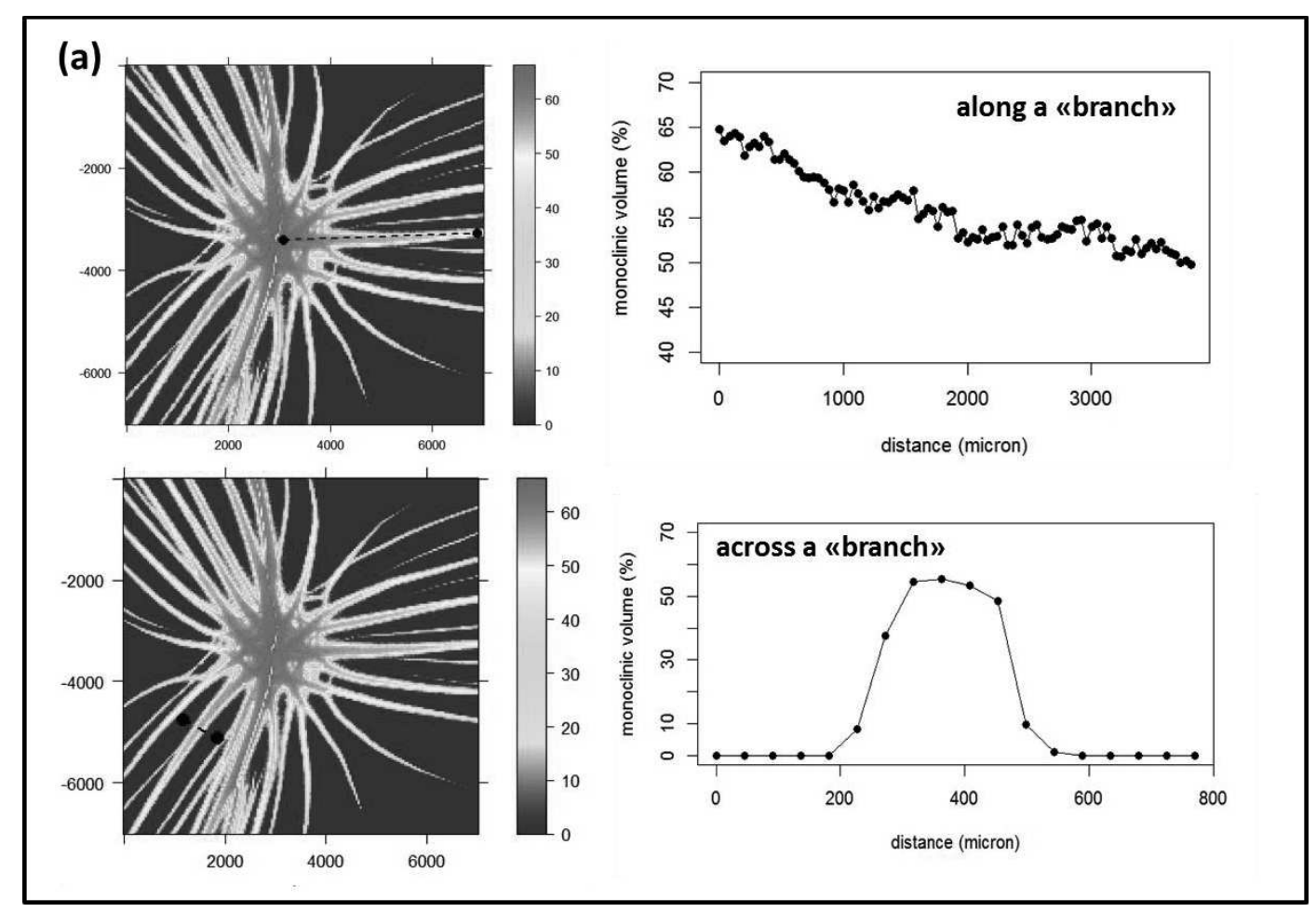

(b)
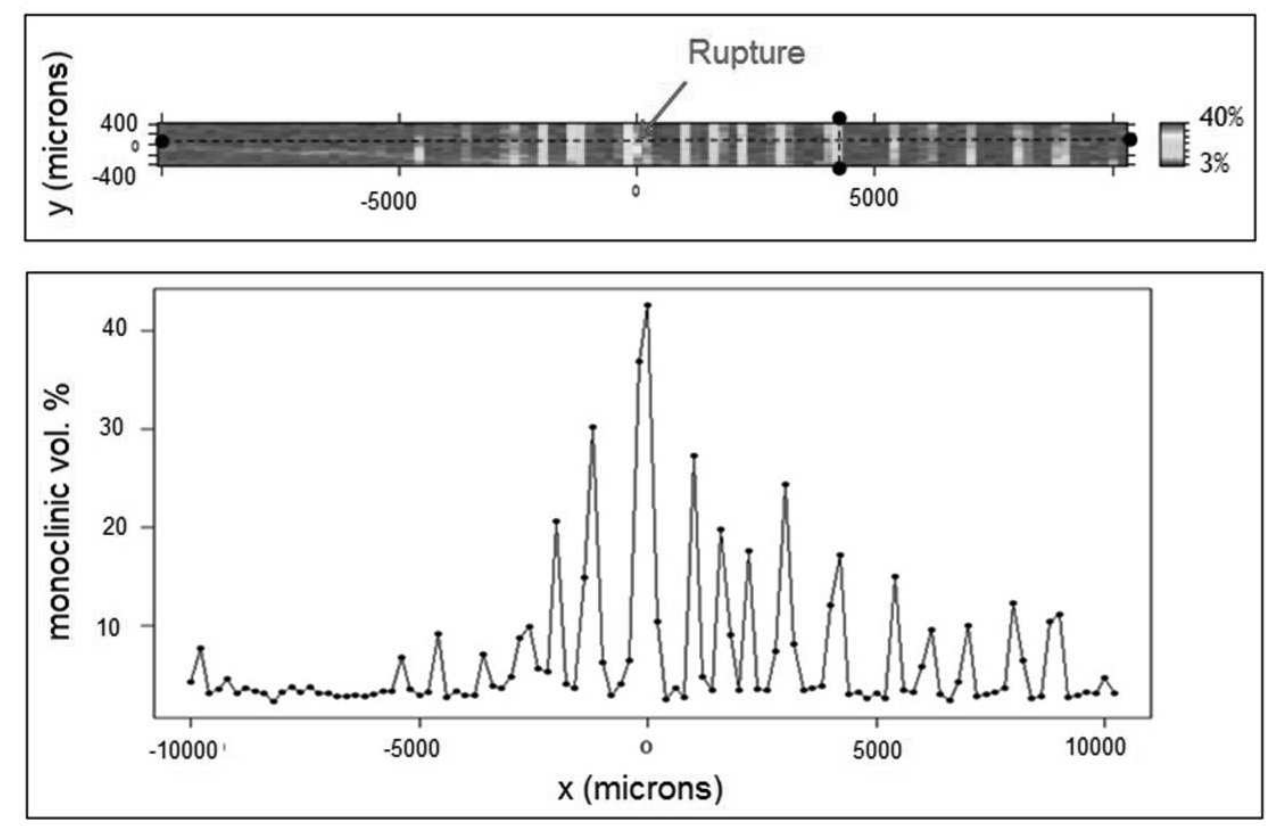

Figure 3. Micro-Raman analysis after (a) P3B and (b) 4PB test of the tensile side of $\mathrm{ZA}_{8} \mathrm{Sr}_{8} \mathrm{Ce}_{11}$ samples. Raman map (false color image) and quantification of the monoclinic volume fraction (a) along or across a branch and (b) along the length of the bending bar are shown. The breakage point was positioned at $\mathrm{x}=0$. Different color codes for P3B and 4PB Raman images have been used. 

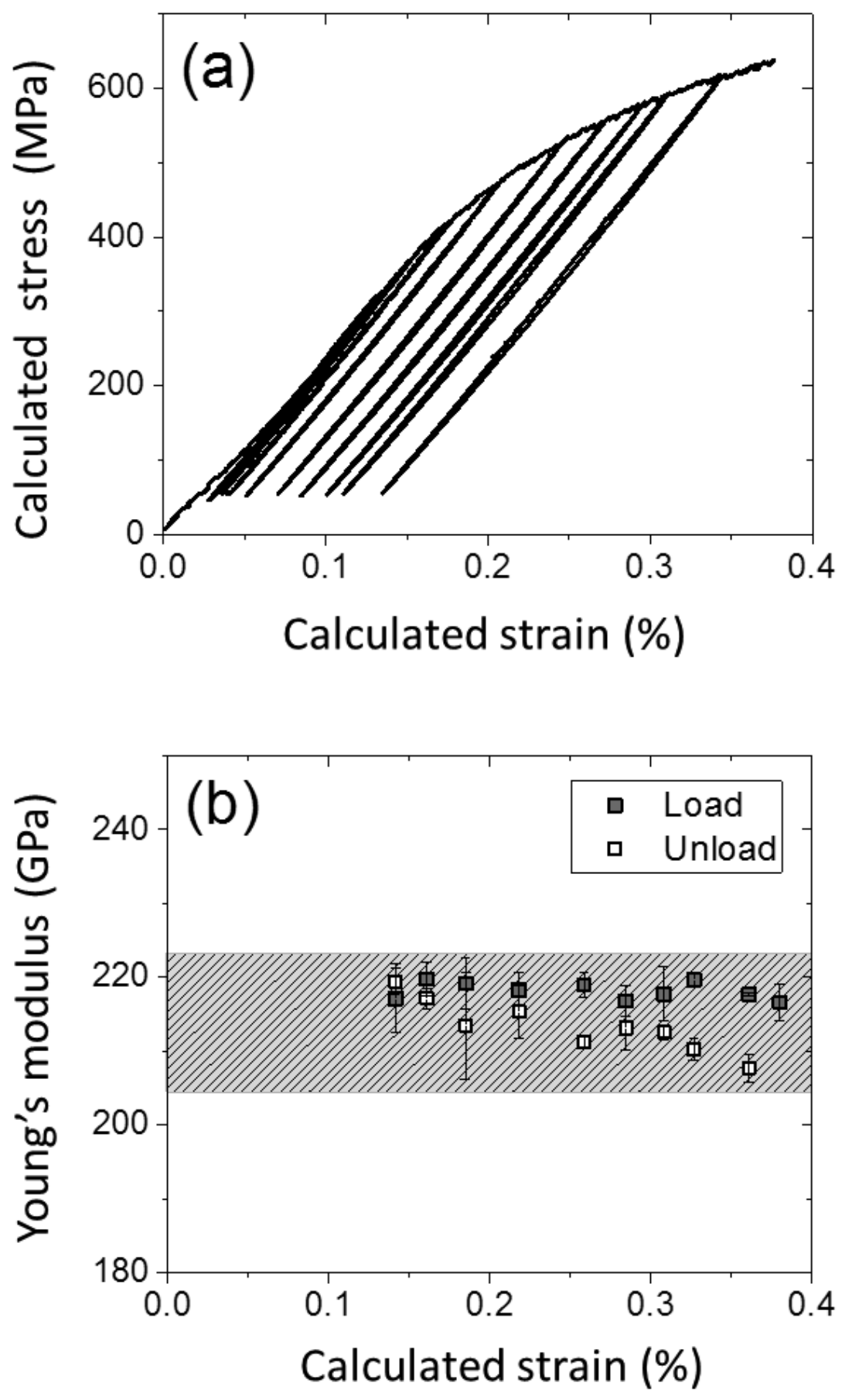

Figure 4. (a) Stress-strain curve of $\mathrm{ZA}_{8} \mathrm{Sr}_{8} \mathrm{Ce}_{11}$ composite obtained during 4PB test. (b) Variation of the Young's modulus computed from the slope of stress-strain load/unload curves. 


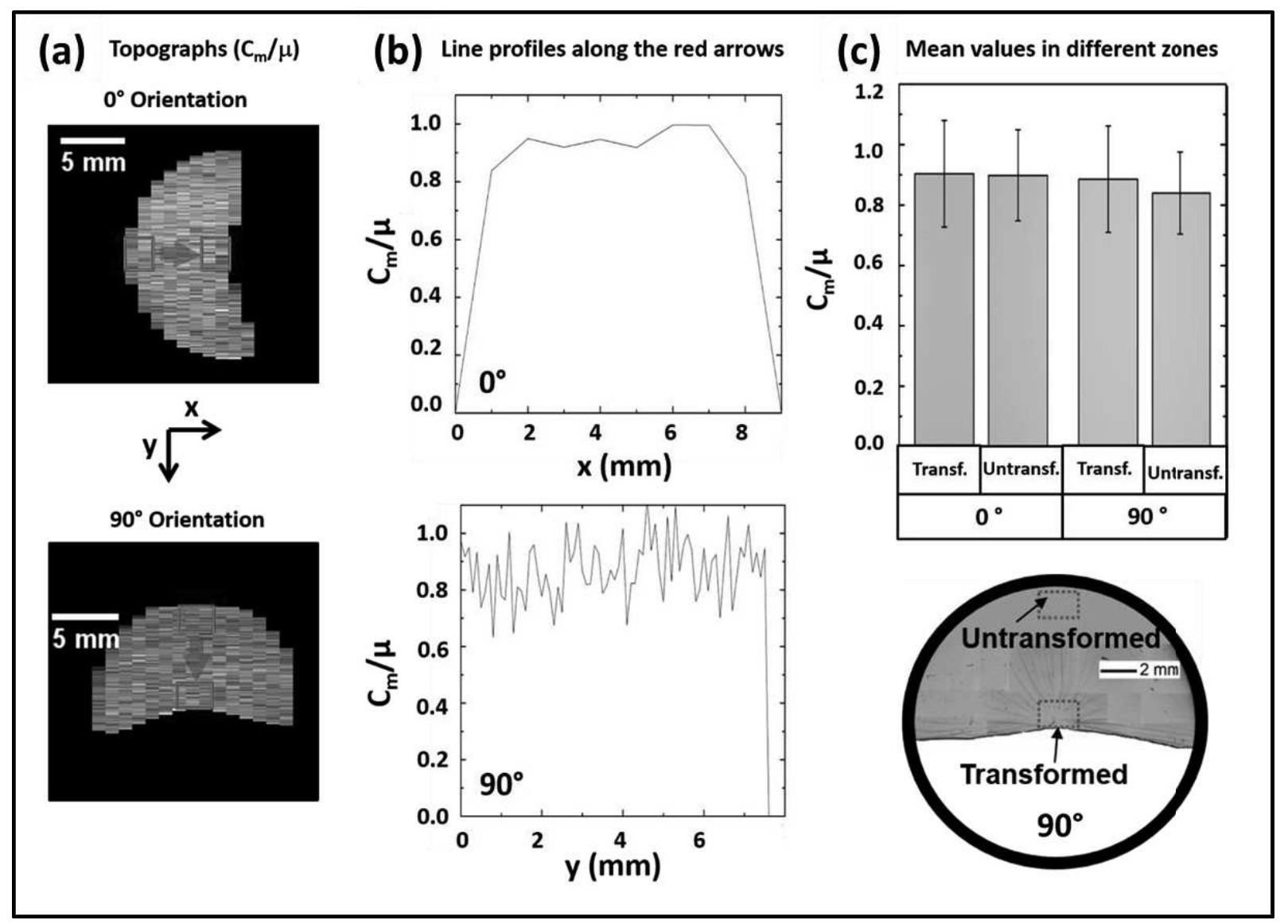

Figure 5. (a) X-ray refraction results in the form of the normalized refraction value $C_{m} / \mu$ maps at $0^{\circ}$ (top) and $90^{\circ}$ orientations (bottom). (b) Corresponding line profiles along the red arrows. (c) Histograms of $\mathrm{C}_{\mathrm{m}} / \mu$ in transformed and untransformed regions in the two perpendicular orientations. Errors bars indicate standard deviation of repeated measurements. Lines profiles at $0^{\circ}$ appear less noisy since the resolution width was $1000 \mu \mathrm{m}(1 \mathrm{point} / \mathrm{mm})$ while at $90^{\circ}$ a higher number of points was considered (height resolution of $50 \mu \mathrm{m}=20$ points $/ \mathrm{mm})$. 


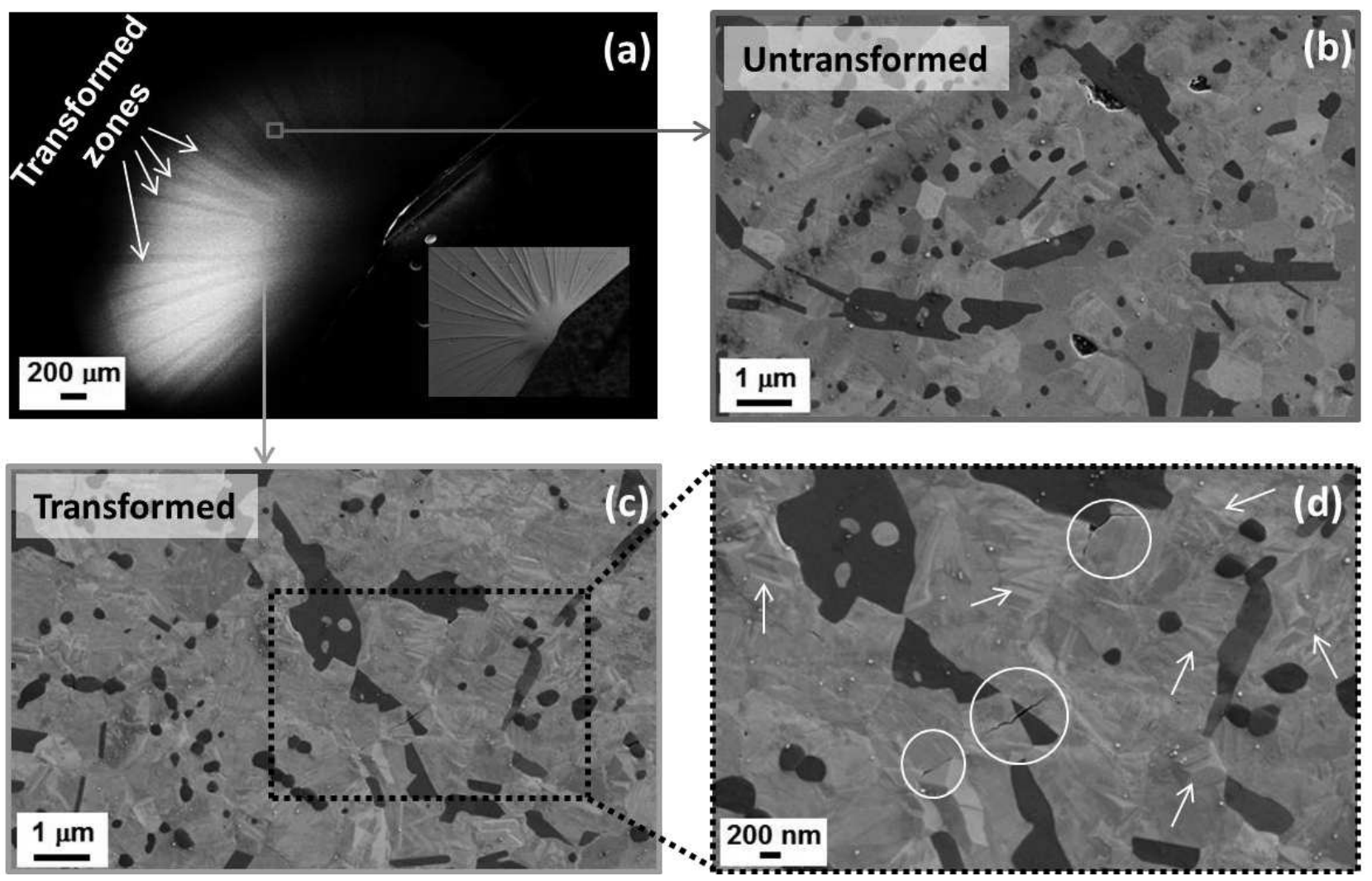

Figure 6. SEM characterization of both transformed and untransformed zones at the tensile surface of a biaxial P3B tested sample. (a) SEM image of the P3B sample with visible transformed zones (the inset shows an optical image). Surface observations show the absence of cracks on untransformed zirconia (b) and few microcracks and debonding (white circles) at the surface of the transformed zone (c,d). Transformed monoclinic grains displaying typical martensitic relief and $m$-laths are indicated with arrows (d). 


\section{Top surface}
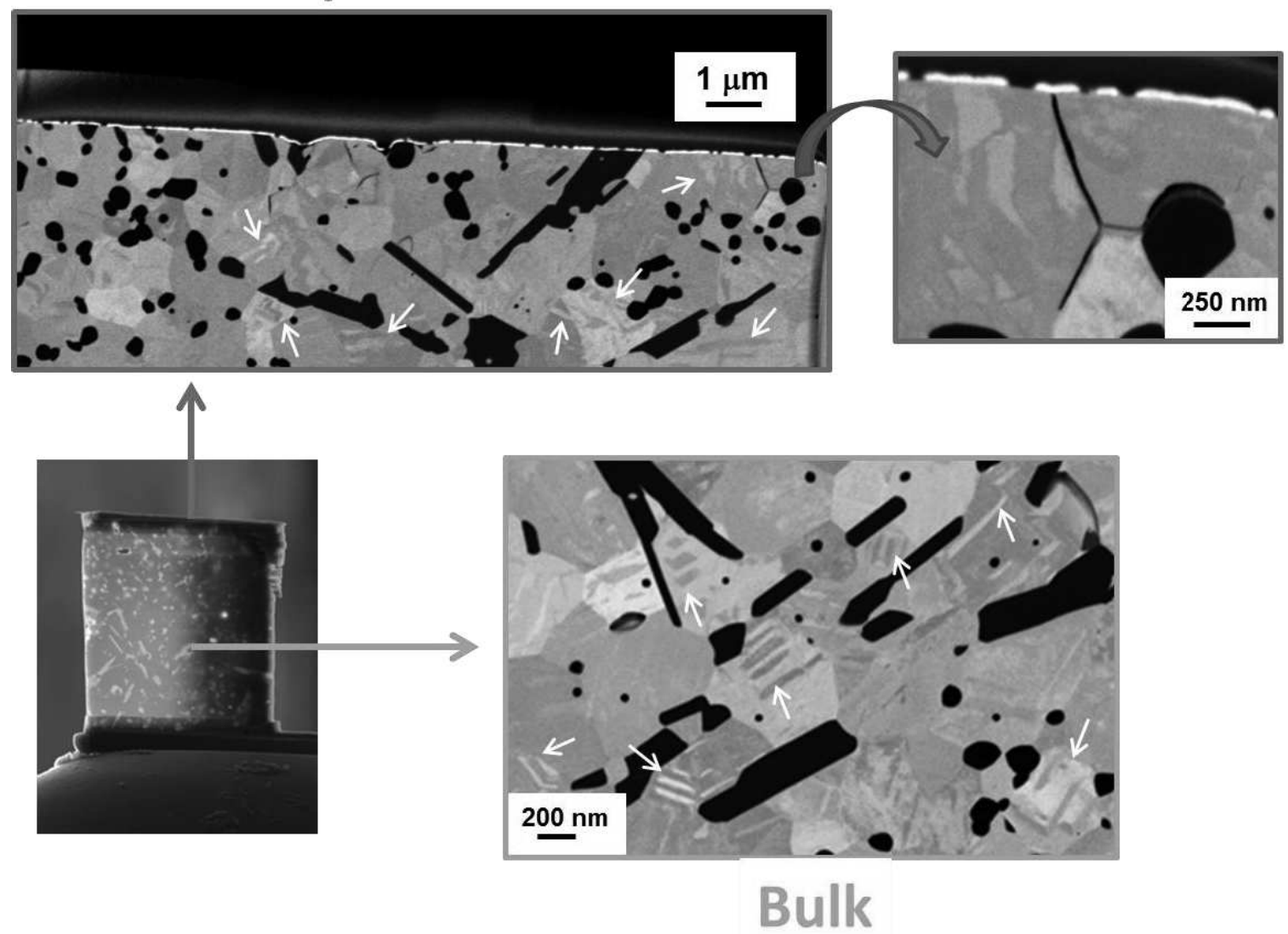

Figure 7. SEM imaging of a FIB cross-section at the surface and inside a 4PB transformation band show very few microcracks at the upper surface of approximately $1 \mu \mathrm{m}$ depth and no cracks inside the transformed zone (bulk). Zirconia transformed grains are clearly recognized by different grey contrast in the shape of "twins" (some of them are indicated by arrows). 

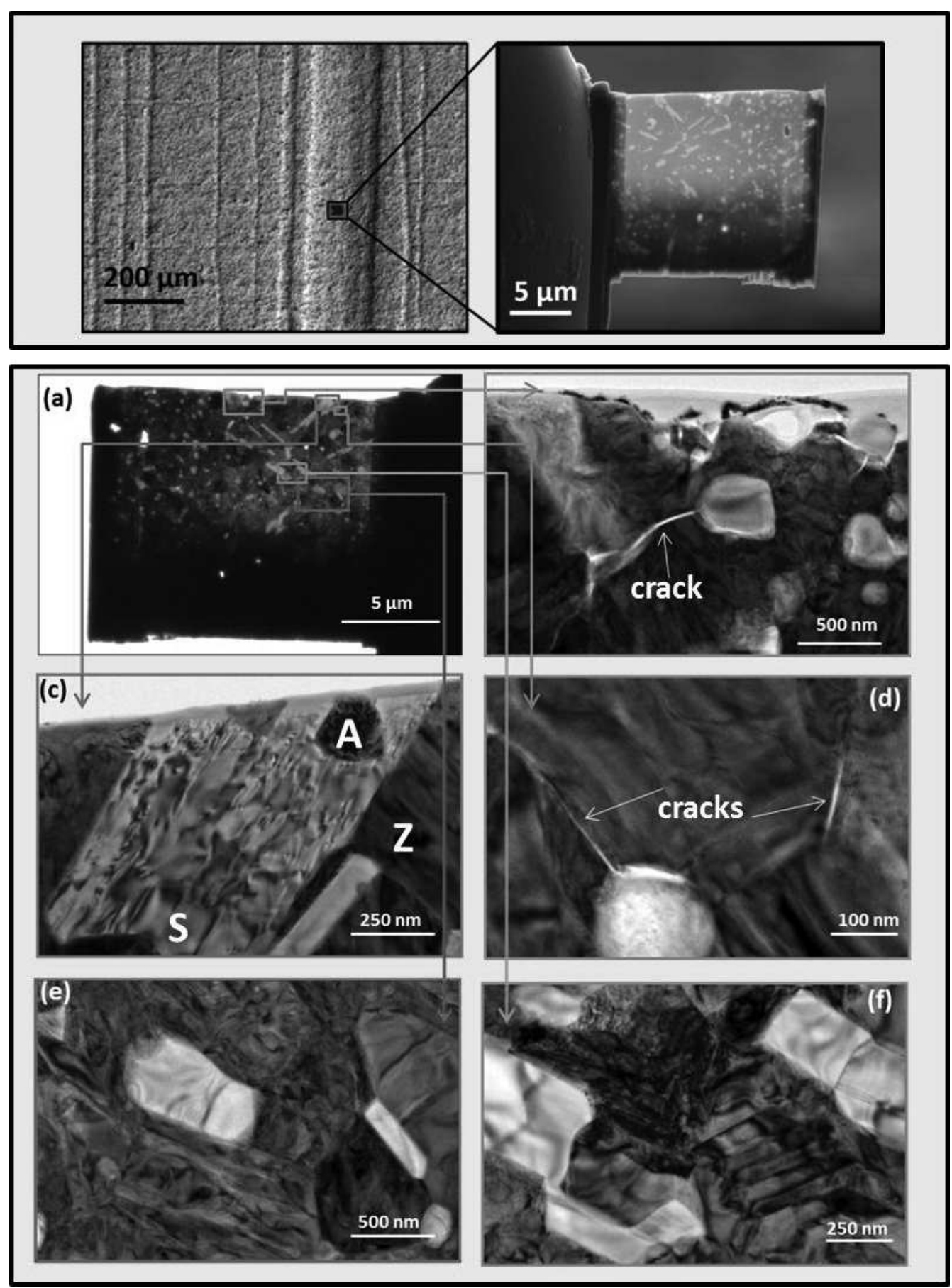

Figure 8. The upper panel shows the location and dimension of the TEM foil obtained by Focus Ion Beam (FIB) milling inside a transformation band: on the left, SEM image of a transformation band visible on a tested $4 \mathrm{~PB}$ sample with the FIB cutting located in the middle of the band. On the right, related TEM foil prepared from the FIB section.

The lower panel shows conventional TEM imaging of the FIB foil (a) extracted from a 4PB transformation band showing very few microcracks near the surface (b, d). (c) Deformed strontium aluminate (S) grain (with dislocation like contrast or Bragg's fringes). (e, f) Deeper inside the transformation band (bulk), no microcracking nor debonding was observed. 
Table 1. Young's modulus values calculated by resonance vibration method before and after plastic deformation (4PB up to $95 \%$ of maximum load).

\begin{tabular}{ccc}
\hline & \multicolumn{2}{c}{ Young's modulus $(\mathbf{G P a} \pm \mathbf{S D})$} \\
\hline Sample $\mathbf{N}^{\circ}$ & Before loading & After loading \\
\hline 1 & $216 \pm 2$ & $216 \pm 2$ \\
2 & $215 \pm 2$ & $215 \pm 2$ \\
\hline
\end{tabular}

